\title{
Expanding interactome analyses beyond model eukaryotes
}

\author{
Katherine James*1, Anil Wipat ${ }^{2}$, and Simon J. Cockell ${ }^{3}$ \\ ${ }^{1}$ Applied Sciences, Northumbria University, Newcastle upon Tyne, UK. \\ ${ }^{2}$ School of Computing, Newcastle University, Newcastle upon Tyne, UK. \\ ${ }^{3}$ School of Biomedical, Nutritional and Sports Sciences, Newcastle University, \\ Newcastle upon Tyne, UK.
}

\begin{abstract}
Interactome analyses have traditionally been applied to yeast, human and other model organisms due to the availability of protein-protein interactions data for these species. Recently these techniques have been applied to more diverse species using computational interaction prediction from genome sequence and other data types. This review describes the various types of computational interactome networks that can be created and how they have been used in diverse eukaryotic species, highlighting some of the key interactome studies in non-model organisms.
\end{abstract}

Key Words: Systems biology; Integrative bioinformatics; Interactomics; Eukaryotes; Non-models; Network biology.

\section{Introduction}

In the early 2000s technologies were developed for high-throughput (HTP) production of genomewide genetic [1-3] and physical interaction data [4-7], allowing genes and their products to be studied in the context of whole cellular systems [8]. Systems approaches can be used to understand the link between genotypes and phenotypes $[9,10]$, the evolution of gene function [11-13], and how cellular biology changes during disease $[14,15]$.

One of the fundamental goals of these analyses is verification of the cellular interactome [16, 17]. The interactome is vital to understanding cellular biology [18] since many biological functions can only be understood as part of the spatio-temporal interactions of the cell [19, 20]. Defining the interactome is not straightforward since the cell contains other molecules that interact with proteins [19, 21, 22]. The associations between genes/proteins can be functional rather than a direct physical interaction, for instance shared complex membership [23-25]. Here the interactome is defined loosely as "the entire complement of functional molecular associations that may occur in a cell" in order to encompass the range of networks discussed.

Interactomes are often represented as networks (graphs) [26], allowing both visual and computational analysis of their structure and connectivity [27-31]. Graph theoretic analyses allows interactome data to be used in a number of ways: detection of protein complexes [32-34]; prediction of protein functions [35-37]; identification of evolutionary relationships [38-41]; and inference

*Corresponding author katherine.p.m.james@northumbria.ac.uk 
of novel interactions that were not detected experimentally [42, 43]. These analyses have been extensively used in yeast and human due to the availability of experimental data for these species. Recently experimental techniques have been applied to more diverse model species and interactomes have been computationally-predicted in non-model organisms using experimental data from other species. Here, we describe the types of interactome networks that can be created and how they have been used in diverse species, highlighting some of the key studies in non-model organisms.

\section{Predicted interactomes}

The detection of the physical binding of proteins, either binary interaction or complex co-membership [44], is the basis for the majority of interactome analyses. Several PPI detection methods, including yeast two-hybrid (Y2H) and affinity purification combined with mass spectometry (AP-MS), have been used to create large-scale interactomes in yeast, humans and other model organiams [4-7, 4551]. Several other methods, such as co-immunoprecipitation (Co-IP) [52], co-fractionation [53], and cross-linking [54], can also be used to detect interaction. Co-IP is often used to confirm interactions detected by $\mathrm{Y} 2 \mathrm{H}$ and AP-MS.

In addition, genetic interactions (GIs) can be detected using a number of methods including RNA interference (RNAi) screens [55], synthetic genetic arrays (SGA) [1], heterozygous diploidbased synthetic lethality analysis on microarrays (dSLAM) [2], and epistatic mini-array profiles (E-MAPs) [3]. Unlike PPI, GIs connect genes with related function, but which protein products are less likely to have a physical interaction [56]; genetically-interacting protein pairs are commonly components of the same pathway or complex and have a relatively high level of conservation across species [57].

Experimental determination of PPI networks is time-consuming, expensive and not currently possible for all species. Therefore, a number of computational methods for the prediction of PPIs have been developed over the past decade and are described in the next sections.

\section{Interologs}

Patterns of protein-protein interaction are conserved [58-60] and interactomes share a set of topological rules [11]. Network 'hubs' (highly-connected proteins) are conserved and often essential [30, 61-63] with slower evolutionary rates and conserved sequences [39, 62, 64-66]. Hubs and key cellular interactions are detectable between eukaryotic species [59], and also between eukaryotes and prokaryotes $[40,58,67]$.

Conserved interactions, termed 'interologs' (direct), 'associologs' (functional) or 'regulogs' (regulatory), can therefore be transferred between species [68-74] providing systems-level network analysis in organisms that lack empirical interaction data (Figure 1). Co-expression patterns are also conserved between species [75, 76] allowing microarray and RNA-seq data to be used to predict functional links between species in the same way $[75,77]$.

\section{Domain-domain and structural interactions}

The conservation of interacting domains can be used to infer interactions since these domains are crucial to proteins' roles and more highly conserved [78-80]; the presence of specific domains in pairs of proteins can be indicative of PPI [79, 81-84]. Protein physiochemical properties, such as charge, hydrophobicity and structure, can be used in combination with domain and sequence to infer interaction [85-87]. The domain-domain interaction (DDI) method is often used in conjunction with interolog mapping [61, 88-92]. 


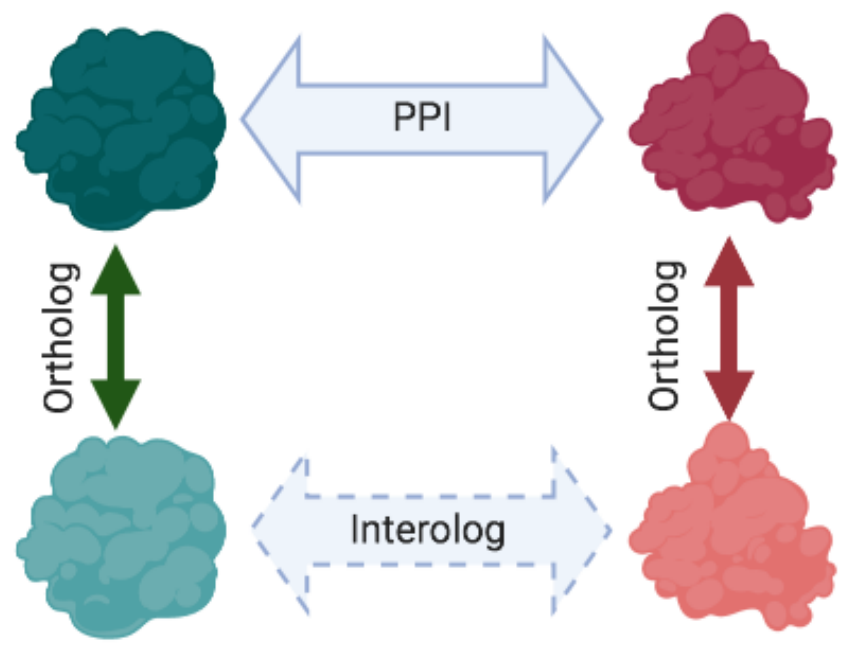

Figure 1: Interologs are mapped from known PPIs via orthology.

The 3D structure of a protein forms an active site essential for its function. It is possible to predict interactions based on these structures, for instance by docking or threading methods [93103], and therefore to predict interactions in species lacking experimental interactome data [104]. Methods that combine sequence and structural data can improve prediction compared with sequence or structure alone $[86,105,106]$. The in silico two-hybrid method (i2H) takes advantage of sequence and structural conservation to predict PPI by comparison of multiple sequence alignments to identify correlated mutations [107].

\section{Genome sequence-based interactions}

Several aspects of genomic sequence can be used to predict PPI [108]. Gene context (GC) can indicate interaction since interacting proteins have increased conservation of their gene order in comparison to non-interacting proteins [109-111]; this prediction method is most accurate in bacterial genomes due to their operons [112], although conservation of gene order has also been observed in mammals [113]. Gene fusion (GF) events can reveal protein interaction since proteins that are fused as a single entity in one species are likely to have a functional link in other species in which they are encoded separately [114-116]. The distribution of gene sequences across species, termed their phylogenetic profile, is also conserved for many interacting pairs [38, 117-122] since they evolve at the same rate [39]. Two genes that have similar profiles are likely to have co-evolved and their products may interact physically or have shared function [123-127].

\section{Integrated interactomes}

The number of interactions common to different experimental datasets can be surprisingly low [33, 128-131] because each individual experiments only measure certain aspects of the cell's behaviour and the resulting datasets are incomplete $[132,133]$. A more complete view of the interactome can be produced by incorporating multiple sources of interaction evidence [134] (Figure $2 \mathrm{~A}$ ). This approach reduces the impact of experimental noise in HTP datasets [23, 135-137] and reveals global properties not evident in a single data type [19]. Integrated networks have advanced our understanding of 
several areas including cellular biology [23, 138], disease processes [14] and evolution [11, 13, 139].

Early interactome studies only linked proteins which had physical interactions (either binary or complex) $[4,5]$. In functional integrated networks, pairs of proteins/genes are linked if they have any type of association; links may represent the gene/proteins' involvement in the same cellular processes without direct interaction [20], for instance via genetic interactions [56], co-localisation [140, 141], or co-citation [142-145]. The greater density of links provided by functional data provides a more informative basis for network analysis than physical interactions alone. Functional networks have been used to analyse data from yeast $[146,147]$ and human [148], and to compare patterns of interaction across multiple species [149].

\section{Probabilistic networks and machine learning}

At the simplest level datasets can be combined naïvely into a network in which nodes represent genes or gene products, and edges represent any type of functional interaction between them [150153] (Figure 2 A). Such networks are useful for the basic visualisation of integrated results but no attention is paid to the amount of evidence for each interaction.

A more useful network can use interaction weights to represent the number of lines of evidence for each interaction (Figure $2 \mathrm{~B}$ ). This weighting provides a measure of confidence since interactions with several sources of evidence are more likely to be true interactions [44, 112, 136, 151, 153-159]. Taking these evidence levels into account allows thresholding of networks to produce high quality sub-networks that are supported by multiple lines of evidence (Figure 2 D) [153, 160-162].

However, the quality of different datasets, in terms of coverage of the genome and accuracy, depends upon the experimental technique used. Probabilistic functional integrated networks (PFINs) take data quality into account by assessing datasets' quality prior to integration (Figure 2 C) [23, $25,147]$. The confidence scores are produced by statistical comparison with a Gold Standard dataset [163-165]: a high-confidence set of interactions believed to be biologically correct [166, 167]. This benchmarking reduces noise from HTP datasets, produces consistent integration of interactions from different studies, and allows the use of thresholding (Figure $2 \mathrm{E}$ ) and statistical algorithms that take these probabilities into account [168]. Probabilistic networks have been created for yeast and a number of other species using a variety of methods and Gold Standards. These networks can then be used to detect protein complexes [32, 169-171], annotate proteins [37, 159, 172] and predict missing interactions [173, 174].

Finally, machine learning approaches can predict PPI using a variety of high quality data types during classifier training [175-181]. The use of multiple data types improves prediction accuracy over single-type prediction methods $[182,183]$. Popular algorithms for PPI prediction include support vector machines [85, 176, 184, 185], random forest algorithms [176, 182, 186-188], and naïve Bayes $[176,189]$.

\section{Computational interactome networks of diverse species}

\section{Fungi}

While the model budding yeast Saccharomyces cerevisiae was the first species to be used in highthroughput interaction screens $[1,2,4-7]$, the model fission yeast Schizosaccharomyces pombe has lagged behind, with few HTP datasets being produced until relatively recently [190-192]. Comparison of the stress-response interactome of $S$. pombe, StressNet, with the network from S. cerevisiae indicated that most stress-related interactions are not conserved and have undergone considerable rewiring during evolution [193]. Binary interactions of S. pombe were found to be better conserved 

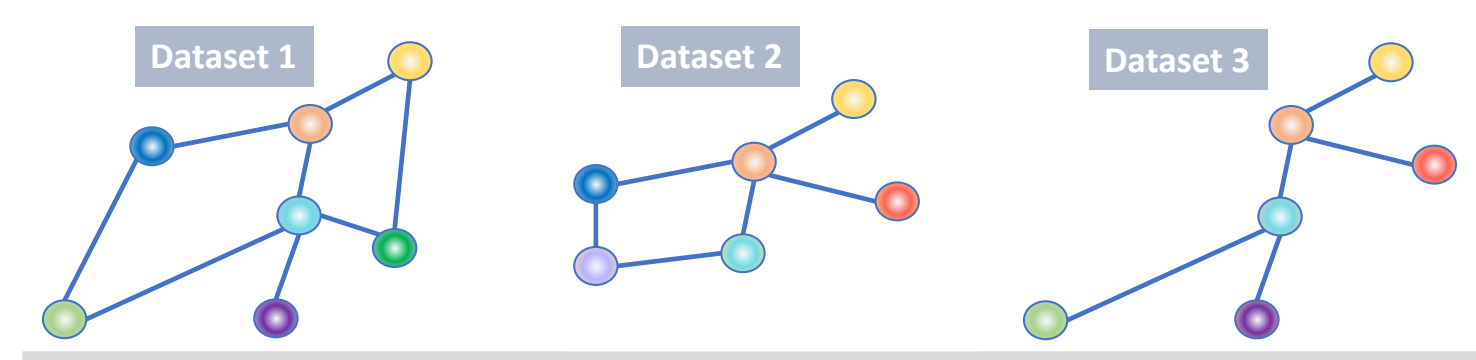

Integration
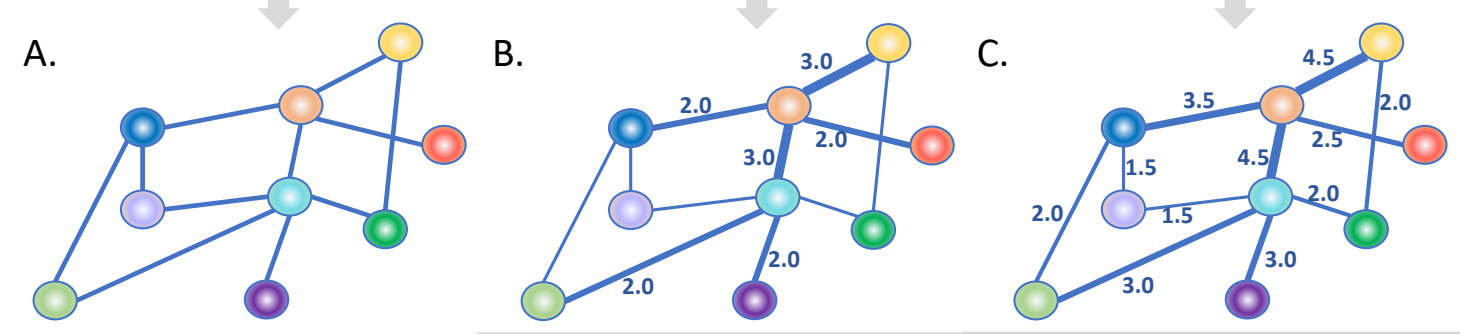

Filtering
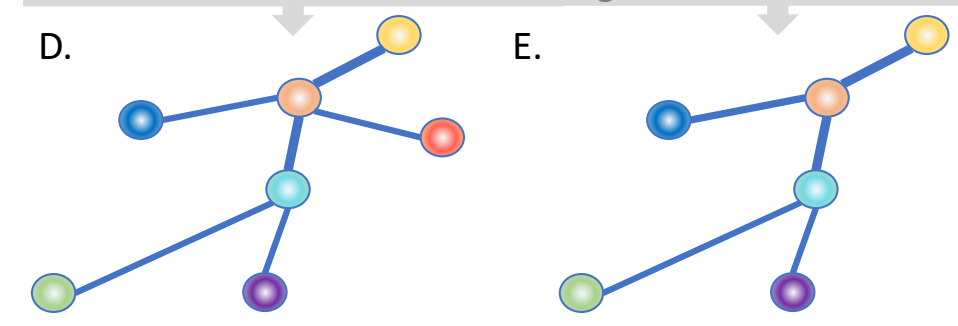

Figure 2: Integration strategies for three datasets measuring interaction (blue lines) between nine proteins (coloured circles). A. The union of the three datasets is produced. B. The interactions are annotated with the number of datasets with evidence for that interaction. C. The datasets have confidence scores (here $\mathrm{A}=2.0, \mathrm{~B}=1.5, \mathrm{C}=1.0$ ) and the interactions are annotated with the sum of these scores. D. Network B can be filtered to select interactions with $>1$ lines of evidence. E. Interaction confidence scores can be filtered to select interactions with high confidence (here $>=3.0$ ). In this case the interaction between the pink and red proteins is lost since it does not pass the threshold despite having two lines of evidence in D.

with humans than with budding yeast, further supporting this evolutionary rewiring [191]. Genetic interactions appear to have higher conservation between $S$. pombe and budding yeast [194], with $\sim 30 \%$ of synthetic lethal interactions found to be conserved [57].

Mass spectroscopy has been used in S. cerevisiae, Candida albicans, and S. pombe to quantify the evolutionary rate of change in phosphorylation, indicating that kinases have a lower rate of conservation, and several of the $S$. pombe results were confirmed using E-MAPs [195]. A more recent E-MAP study suggested a hierarchical model for the evolution of genetic interactions [196]. Despite the evidence for evolutionary rewiring of $S$. pombe PPIs, it is possible to use $S$. cerevisiae and other data to computationally predict $S$. pombe interactions [188, 197, 198]. In particular the Pombe Interactome was predicted using over 100 protein features by comparison with budding yeast and several predicted interactions for the Cbf11 transcription factor were subsequently confirmed 
using AP-MS [199].

Table 1: Computational interactomes in Candida albicans and other budding yeasts.

\begin{tabular}{llrrr} 
Species & Methodology & Proteins & Interactions & Ref \\
\hline Candida albicans & Literature curated & - & 1,208 & {$[200]$} \\
& Machine learning & 284 & 398 & {$[188]$} \\
Candida dubliniensis & Integrated & 1,272 & 4,699 & {$[13]$} \\
Candida glabrata & Machine learning & 2,005 & 5,089 & {$[188]$} \\
& Integrated & 1,423 & 5,421 & {$[13]$} \\
Candida tropicalis & Integrated & 1,305 & 4,941 & {$[13]$} \\
Clavispora lusitaniae & Integrated & 1,254 & 4,524 & {$[13]$} \\
Debaryomyces hansenii & Machine learning & 1,229 & 2,338 & {$[188]$} \\
Eremothecium gossypii & Integrated & 1,346 & 4,757 & {$[13]$} \\
& Machine learning & 1,014 & 1,971 & {$[188]$} \\
Eremothecium cymbalariae & Integrated & 1,087 & 3,441 & {$[13]$} \\
Kluyveromyces lactis & Integrated & 1,437 & 5,636 & {$[13]$} \\
& Machine learning & 1,658 & 38,20 & {$[188]$} \\
Komagataella phaffii & Integrated & 1,160 & 3,948 & {$[13]$} \\
Lachancea thermotolerans & Integrated & 1,264 & 4,531 & {$[13]$} \\
Lodderomyces elongisporus & Integrated & 1,225 & 4,284 & {$[13]$} \\
& Machine learning & 1,024 & 1,914 & {$[188]$} \\
Meyerozyma guilliermondii & Integrated & 1,313 & 4,964 & {$[13]$} \\
Naumovozyma castellii & Integrated & 1,432 & 5,197 & {$[13]$} \\
Naumovozyma dairenensis & Integrated & 1,424 & 5,289 & {$[13]$} \\
Scheffersomyces stipitis & Integrated & 1,323 & 5,230 & {$[13]$} \\
& Machine learning & 1,000 & 1,754 & {$[188]$} \\
Tetrapisispora phaffii & Integrated & 1,376 & 4,848 & {$[13]$} \\
Torulaspora delbrueckii & Integrated & 1,246 & 4,395 & {$[13]$} \\
Vanderwaltozyma polyspora & Integrated & 1,294 & 4,349 & {$[13]$} \\
Yarrowia lipolytica & Integrated & 1,264 & 4,605 & {$[13]$} \\
& Machine learning & 1,072 & 1,810 & {$[188]$} \\
Zygosaccharomyces rouxii & Integrated & 1,250 & 4,265 & {$[13]$} \\
\hline \hline
\end{tabular}

Candida albicans is a budding yeast and opportunistic pathogen found in the human gut [201]. Production of interaction data in this species has lagged behind other yeasts due to non-standard codon usage [202], which requires modified methodologies [203-205]. Schoeters and colleagues have provided a manually curated list C. albicans protein-protein interaction data [200] and several other interactome datasets have been produced in this and other budding yeasts (Table 1). Ascomycetes and other Fungi have also been investigated using computational network prediction (Tables 2 and 3). The PHI-Nets resource contains networks, produced using interologs and DDI mapping from S. cerevisiae and S. pombe, for fifteen Ascomycetes [206] including the pathogenic fungi Aspergillus fumigatus [207] and Fusarium graminearum [208]. The FPPI database is a resource for F. graminearum, which provides confidence scored interologs covering $\sim 52 \%$ of the proteome [88]. In a later study, FPPI interactions were combined with gene expression data to predict a subnetwork of pathogenicity genes; two interconnected network modules were identified that were enriched in G-protein coupled receptors and MAPK signalling pathways, and which contained several known pathogenicity genes [209]. Finally, a large-scale study by Zitnik and colleagues produced computa- 
tionally predicted networks for over 40 fungi [13].

Combining networks from pathogenic yeasts and their hosts aids understanding of infection processes and can identify potential drug targets. Microarray data from C. albicans infected zebrafish were used to predict networks at different stages of infection and decipher the mechanisms underlying $C$. albicans pathogenicity [210]. Time-course C. albicans-zebrafish transcriptomics mapped to interolog networks indicated that redox status is crucial to infection in this species [211]. Similarly, comparison of the early and late stages of C. albicans infection identified important functional modules in both the pathogenic and defensive mechanisms [212]. Remmele and co-workers used interolog mapping to identify host-pathogen interactions of $A$. fumigatus during human and mouse infection, highlighting the roles of the PLB1 virulence factor and APP anti-fungal host protein [213]. Several network studies have also investigated yeast infection in plants [61, 89, 91, 214-217].

Table 2: Computational interactomes in Ascomycetes yeasts. DDI: domain-domain interactions; PFIN: probabilistic functional integrated network.

\begin{tabular}{|c|c|c|c|c|}
\hline Species & Methodology & Proteins & Interactions & Ref \\
\hline Aspergillus clavatus & Integrated & 1,479 & 6,747 & [13] \\
\hline Aspergillus fischeri & Integrated & 1,577 & 8,010 & [13] \\
\hline Aspergillus flavus & Integrated & 1,668 & 9,044 & {$[13]$} \\
\hline \multirow[t]{3}{*}{ Aspergillus fumigatus } & Interolog, DDI & 5,925 & 277,441 & [206] \\
\hline & Integrated & 1,537 & 8,028 & [13] \\
\hline & Machine learning & 813 & 1,300 & {$[188]$} \\
\hline Aspergillus oryzae & Integrated & 1,400 & 6,125 & [13] \\
\hline \multirow[t]{2}{*}{ Aspergillus nidulans } & Integrated & 1,459 & 6,792 & [13] \\
\hline & Machine learning & 921 & 1,521 & {$[188]$} \\
\hline Aspergillus niger & Integrated & 1,279 & 5,391 & [13] \\
\hline Bipolaris sorokiniana & Interolog, DDI & 5,389 & 264,403 & {$[206]$} \\
\hline Blumeria graminis & Interolog, DDI & 3,816 & 154,218 & {$[206]$} \\
\hline \multirow[t]{3}{*}{ Botrytis cinerea } & Interolog, DDI & 6,416 & 344,586 & {$[206]$} \\
\hline & Integrated & 1,315 & 5,028 & [13] \\
\hline & Machine learning & 852 & 1,387 & {$[188]$} \\
\hline Coccidioides immitis & Integrated & 1,193 & 4,448 & [13] \\
\hline Coccidioides posadasii & Integrated & 1,228 & 4,638 & [13] \\
\hline Colletotrichum gloeosporioides & Interolog, DDI & 8,161 & 444,775 & {$[206]$} \\
\hline Colletotrichum graminicola & Interolog, DDI & 6,514 & 297,282 & {$[206]$} \\
\hline \multirow[t]{3}{*}{ Fusarium graminearum } & PFIN & 7,406 & 223,166 & [88] \\
\hline & PFIN, gene expression & 127 & 259 & [209] \\
\hline & Interolog, DDI & 7,062 & 381,518 & {$[206]$} \\
\hline Fusarium oxysporum & Interolog, DDI & 8,292 & 452,631 & {$[206]$} \\
\hline Fusarium solani & Integrated & 1,842 & 12,418 & {$[13]$} \\
\hline Fusarium verticillioides & Interolog, DDI & 7,094 & 334,015 & {$[206]$} \\
\hline Histoplasma capsulatum & Integrated & 1,200 & 4,358 & [13] \\
\hline Leptosphaeria maculans & Interolog, DDI & 5,327 & 221,687 & {$[206]$} \\
\hline \multirow[t]{2}{*}{ Magnaporthe (Pyricularia) grisea } & Interolog & 3,017 & 11,674 & [61] \\
\hline & Machine learning & 629 & 953 & [188] \\
\hline Magnaporthe (Pyricularia) oryzae & Interolog, DDI & 6,071 & 287,159 & {$[206]$} \\
\hline
\end{tabular}


Table 2 - continued from previous page

\begin{tabular}{llrrr} 
Species & Methodology & Proteins & Interactions & Ref \\
\hline & Integrated & 1,304 & 5,028 & {$[13]$} \\
Neurospora crassa & Interolog, DDI & 3,006 & 27,588 & {$[218]$} \\
& Integrated & 1,364 & 5,028 & {$[13]$} \\
& Machine learning & 1,161 & 2,186 & {$[188]$} \\
Paracoccidioides lutzii & Integrated & 1,124 & 3,963 & {$[13]$} \\
Parastagonospora nodorum & Integrated & 1,499 & 6,759 & {$[13]$} \\
& Machine learning & 255 & 250 & {$[188]$} \\
Phomopsis longicolla & Interolog & 3,868 & 215,255 & {$[217]$} \\
Penicillium rubens & Integrated & 1,597 & 7,358 & {$[13]$} \\
Podospora anserina & Integrated & 1,423 & 5,847 & {$[13]$} \\
Pyrenophora teres & Integrated & 1,450 & 6,372 & {$[13]$} \\
Sclerotinia sclerotiorum & Interolog, DDI & 3,803 & 118,987 & {$[206]$} \\
& Integrated & 856 & 2,400 & {$[13]$} \\
Sordaria macrospora & Integrated & 1,333 & 5,270 & {$[13]$} \\
Thermothelomyces thermophilus & Integrated & 1,339 & 5,216 & {$[13]$} \\
Thermothielavioides terrestris & Integrated & 1,357 & 5,171 & {$[13]$} \\
Trichoderma reesei & Integrated & 1,336 & 5,194 & {$[13]$} \\
Trichophyton benhamiae & Integrated & 1,206 & 4,366 & {$[13]$} \\
Trichophyton rubrum & Integrated & 186 & 1,139 & {$[216]$} \\
Trichophyton verrucosum & Integrated & 1,206 & 4,567 & {$[13]$} \\
Tuber melanosporum & Integrated & 1,135 & 3,907 & {$[13]$} \\
Uncinocarpus reesii & Integrated & 1,153 & 4,422 & {$[13]$} \\
Ustilaginoidea virens & Interolog, DDI & 3,305 & 20,217 & {$[89]$} \\
& Machine learning & 604 & 943 & {$[188]$} \\
Verticillium alfalfae & Integrated & 1,421 & 6,182 & {$[13]$} \\
Verticillium dahliae & Interolog, DDI & 5,801 & 247,581 & {$[206]$} \\
Zymoseptoria tritici & Interolog, DDI & 5,609 & 251,215 & {$[206]$} \\
\hline \hline & & & &
\end{tabular}

\section{Plants}

The plant Arabidopsis thaliana, thale cress, was chosen as the first 'model' plant due to its small genome since and diploid nature that made genetic manipulation relatively simple [219]. A. thaliana has most well-characterised interactome of the plants with several experimental [220-227] and computational datasets [13, 149, 187, 188, 198, 228-238], many of which form the basis of interactome studies in other plants [238-243]. Cross-species interactomes have also investigated infection in this species $[215,244]$.

More recently, new plant models have been developed [219] and several interactome studies have been carried out in other plant species, many of which have commercial value (Table 4). Unlike A. thaliana, very little interaction data have been produced for rice, Oryza sativa, despite its economic importance as a staple food. The majority of interactome networks in this species were computationally-predicted, although some experimental data have been produced [245-247]. Interolog mapping was used to create a proteome-wide interactome for rice, which correlated well 
Table 3: Computational interactomes in other yeasts. DDI: domain-domain interactions.

\begin{tabular}{llrrr} 
Species & Methodology & Proteins & Interactions & Ref \\
\hline Coprinopsis cinerea & Integrated & 1,396 & 5,436 & {$[13]$} \\
Cryptococcus neoformans & Integrated & 1,134 & 3,986 & {$[13]$} \\
& Machine learning & 1,006 & 2,004 & {$[188]$} \\
Cryptococcus gattii & Integrated & 1,130 & 4,019 & {$[13]$} \\
Encephalitozoon intestinalis & Integrated & 246 & 591 & {$[13]$} \\
Encephalitozoon hellem & Integrated & 254 & 607 & {$[13]$} \\
Encephalitozoon cuniculi & Integrated & 265 & 574 & {$[13]$} \\
& Machine learning & 154 & 200 & {$[188]$} \\
Laccaria bicolor & Integrated & 1,384 & 5,507 & {$[13]$} \\
Malassezia globosa & Integrated & 907 & 2,636 & {$[13]$} \\
Puccinia graminis & Integrated & 1,353 & 4,449 & {$[13]$} \\
Rhizoctonia solani & Interolog, DDI & 1,773 & 6,705 & {$[91]$} \\
Schizophyllum commune & Integrated & 1,405 & 5,382 & {$[13]$} \\
\hline \hline
\end{tabular}

with co-expression data [248]. RicePPINet used structural and functional information as machine learning inputs to predict the rice interactome and the resulting network was used to identify genes involved in disease resistance and drought tolerance [249]. PlaPPISite comprises 36,420 interologs predicted using several computational methods [238], while the predicted Rice Interactome Network, PRIN, contains 76,585 interologs [250, 251]. RiceNet is a PFIN for rice produced using data from several model organisms [252]; an updated RiceNet network has 1,775,000 interactions between 25,765 genes [253].

BarleyNet is a PFIN for barley, Hordeum vulgare, based on orthology to Arabidopsis and rice [254]. Five computationally-predicted interactomes were produced for Zea mays, maize [13, 231, 238, 239, 255]. In horse gram, Macrotyloma uniflorum, an interolog network of over 6,000 interactions has been produced [256]. Predicted interactomes have also been created for many other plant species (Table 4). For instance, PTIR is a tomato interolog network based on orthology to six model organisms containing over 12,000 high confidence interactions, ten of which were experimentally verified [257]. A turnip (Brassica rapa) interolog network has been inferred from A. thalina data [258] and a predicted interactome was produced for coffee, Coffea canephora, using orthology to model organisms including $A$. thalaina [259]. Predicted networks have also been built for the tea plant Camellia sinensis [92, 260], cassava Manihot esculenta [261, 262], orange Citrus sinensis [263], thai basil, Ocimum tenuiflorum [264], the poplar tree Populus trichocarpa, and the moss Physcomitrella patens [187].

Compuatational methods have been used to compare networks between multiple plant species. For instance, PlaPPISite contains interolog networks for eleven other plant species inferred using structural and domain information which provides accurate prediction of interaction sites in these species [238]. Ding and colleagues used functional interaction data to infer confidence-scored interolog networks for three species - A. thaliana, Glycine max (soybean) and Z. mays - many interactions of which were supported by literature curated evidence [231]. Vandereyken and co-workers compared hub proteins between major plant interactome studies and found that many are involved in stress responses [265]. Zitnik and colleagues' large-scale interactome study created networks for sixteen plant species [13]. Finally, several studies have produced plant-pathogen networks [89, 266]. Fungal-plant networks are discussed above and reviewed in [267]. 
Table 4: Computational interactomes in plants. DDI: domain-domain interaction; PFIN: probabilisitc functional integrated network.

\begin{tabular}{|c|c|c|c|c|}
\hline Species & Methodology & Proteins & Interactions & Ref \\
\hline Arabidopsis lyrata & Integrated & 3,979 & 37,163 & [13] \\
\hline \multirow[t]{2}{*}{ Brachypodium distachyon } & Interolog & - & 105,705 & [238] \\
\hline & Integrated & 3,326 & 25,063 & {$[13]$} \\
\hline Brassica rapa & Interolog, DDI & - & 723,310 & [258] \\
\hline \multirow[t]{2}{*}{ Camellia sinensis } & Interolog, gene expression & 11,208 & 197,820 & [260] \\
\hline & Interolog, DDI & 12,033 & 216,107 & {$[92]$} \\
\hline \multirow[t]{3}{*}{ Chlamydomonas reinhardtii } & Interolog & - & 49,350 & [238] \\
\hline & Phylogenetic profile & 1,086 & 11,094 & [268] \\
\hline & Integrated & 1,449 & 8,207 & {$[13]$} \\
\hline Citrus sinensis & Interolog & 8,195 & 124,491 & [263] \\
\hline Coffea canephora & Interolog & 939 & 4,587 & [259] \\
\hline \multirow[t]{3}{*}{ Glycine $\max$} & Interolog & - & 160,024 & [238] \\
\hline & Machine learning & - & $13,527,834$ & [231] \\
\hline & Integrated & 5,785 & 89,538 & {$[13]$} \\
\hline \multirow[t]{2}{*}{ Hordeum vulgare } & PFIN & 26,145 & $1,272,200$ & [254] \\
\hline & Integrated & 50 & 152 & {$[13]$} \\
\hline Macrotyloma uniflorum & Interolog, DDI & 1,812 & 6,804 & [256] \\
\hline \multirow[t]{2}{*}{ Manihot esculenta } & Interolog, gene expression & 24,590 & $3,638,916$ & [262] \\
\hline & Interolog & 7,209 & 90,173 & [261] \\
\hline Medicago truncatula & Interolog & - & 112,478 & [238] \\
\hline Ocimum tenuiflorum & Interolog & 13,660 & 327,409 & [264] \\
\hline \multirow[t]{10}{*}{ Oryza sativa } & Machine learning & 16,895 & 708,819 & [249] \\
\hline & Machine learning & 716 & 1,341 & [188] \\
\hline & Interolog & - & 99,296 & [238] \\
\hline & Interolog & 5,049 & 76,585 & [250] \\
\hline & Interolog, gene expression & - & 9,132 & [269] \\
\hline & PFIN & 18,377 & 588,221 & {$[252]$} \\
\hline & PFIN & 25,765 & $1,775,000$ & [253] \\
\hline & PFIN & 4,567 & 35,441 & [248] \\
\hline & PFIN & 12,184 & $2,996,703$ & [198] \\
\hline & Interolog & 27,746 & $14,614,067$ & {$[270]$} \\
\hline Oryza sativa Indica Group & Integrated & 105 & 224 & {$[13]$} \\
\hline Oryza sativa Japonica Group & Integrated & 1,787 & 54,247 & {$[13]$} \\
\hline Oryza brachyantha & Integrated & 2,946 & 23,484 & [13] \\
\hline Oryza glaberrima & Integrated & 35 & 100 & {$[13]$} \\
\hline Ostreococcus tauri & Integrated & 895 & 3,107 & [13] \\
\hline Ostreococcus lucimarinus & Integrated & 1,000 & 3,855 & [13] \\
\hline \multirow[t]{2}{*}{ Physcomitrella patens } & Interolog & 5,695 & 67,740 & [271] \\
\hline & Integrated & 3,190 & 31,790 & {$[13]$} \\
\hline \multirow[t]{4}{*}{ Populus trichocarpa } & Machine learning & 19,321 & 481,253 & {$[187]$} \\
\hline & Interolog & - & 135,876 & [238] \\
\hline & Integrated & 4,914 & 60,001 & {$[13]$} \\
\hline & Machine learning & 1,654 & 5,536 & [188] \\
\hline
\end{tabular}


Table 4 - continued from previous page

\begin{tabular}{llrrr} 
Species & Methodology & Proteins & Interactions & Ref \\
\hline Ricinus communis & Interolog & - & 99,157 & {$[238]$} \\
Selaginella moellendorffi & Interolog & - & 112,480 & {$[238]$} \\
& Integrated & 4,345 & 52,874 & {$[13]$} \\
Setaria italica & Integrated & 3,403 & 27,827 & {$[13]$} \\
Solanum lycopersicum & Interolog & 10,626 & 35,7946 & {$[257]$} \\
& Interolog & - & 110,943 & {$[238]$} \\
& Integrated & 3,601 & 32,470 & {$[13]$} \\
Solanum tuberosum & Integrated & 3,239 & 27,478 & {$[13]$} \\
& Interolog & - & 81,057 & {$[238]$} \\
Solanum bicolor & Integrated & 3,503 & 26,577 & {$[13]$} \\
Tetraselmis subcordiformis & Machine learning & 751 & 1,874 & {$[188]$} \\
Vitis vinifera & Interolog, DDI & 938 & 7,773 & {$[272]$} \\
& Interolog & - & 105,415 & {$[238]$} \\
& Integrated & 3,418 & 28,243 & {$[13]$} \\
Zea mays & Machine learning & 276 & 503 & {$[188]$} \\
& Interolog & 6,004 & 49,026 & {$[255]$} \\
& Interolog & - & 112,597 & {$[238]$} \\
& Machine learning & 14,000 & $2,762,560$ & {$[273]$} \\
& Machine learning & - & $13,175,414$ & {$[231]$} \\
& Integrated & 2,849 & 18,046 & {$[13]$} \\
& PFIN & 26,624 & 922,039 & {$[274]$} \\
\hline \hline
\end{tabular}

\section{Protozoa}

The apicomplexan Plasmodium falciparum is the causative agent of malaria [275]. Interactome analysis is a powerful method for understanding this parasite and identifying potential targets for therapeutic intervention. Few large-scale interaction screens have been carried out in P. falciparum due to its AT-rich genome hampering classical experimental methodologies such as yeast two hybrid [276]. A comparison of the P. falpicarum interactome [277] with those of yeast, worm, fly and human revealed a marked difference in hub connectivity in the malarial network, with clustered interconnected hubs [278]. This divergence from other species has also been observed in $P$. falciparum's protein complex conservation [279].

Computational prediction has been applied to host-malaria infection. Dyer and co-workers integrated intra-species PPIs with protein-domain profiles to predict PPIs between P. falciparum and its human host [280]. Interolog mapping using eighteen other eukaryotic species was used to produce an interactome for P. falciparum and predict its interactions with human proteins [70]. A later interolog study based on multiple interaction datasets revealed parasite proteins predominantly target hub proteins to take control of the human host cell [281]. An integrated interactome of predicted and experimental data was used to study the pathogenesis of cerebral malaria [282] and in the related species, $P$. vivax, machine learning was used to create a human-malaria interactome that was analysed to identify putative drug targets [283].

Leishmania and Trypanosoma are groups of protazoan parasites that cause disease in humansLeishmaniasis and Chagas disease/sleeping sickness, respectively [284-286] — for which there are 
several interactome datasets. Interactome networks for Leishmania braziliensis and Leishmania infantum were produced by Dos Santos Vasconce and colleagues based on structural data and machine learning [287]. These predicted networks, were later enhanced by incorporating data from an interolog mapping study in which networks were produced for three Leishmania species, L. braziliensis, L. major and L. infantum before confidence evaluation using gold standard data [288].

To identify potential drug targets for Chagas disease, the predicted secretome for this and the insect pathogen Trypanosoma rangeli, were computationally mapped to cellular pathways [289]. Expression data were mapped to interolog networks of T. brucei and its vector Glossina morsitans morsitans to identify genes and proteins involved in the response to infection [290]. In a later study, interolog mapping identified interactions between T. brucei and G. m. morsitans [291]. TrypsNetDB contains experimental and interolog interactions for several Leishmania and Trypanosoma [292].

Several other interactome studies have been carried out in protozoans (Table 5). Date and colleagues created a probabilistic functional integrated network for P. falciparum and mapped the network to T. gondii, and C. parvum, to identify areas of commonality [293]. Twenty three protozoan networks were produced in a study of 68 eukaryotic integrated interactomes [13]. Finally, Cuesta-Astroz and colleague's large-scale study of fifteen parasite-host interolog networks including Plasmodiums, Trypanosomas , Leishmanias and other apicomplexan parasites [294].

Table 5: Computational interactomes in protozoans. DDI: domain-domain interaction; PFIN: probabilisitc functional integrated network. ${ }^{*} P$. yoelii, Toxoplasma gondii, and Cryptosporidium parvum. ** P. falciparum, P. knowlesi, and P. berghei.

\begin{tabular}{|c|c|c|c|c|}
\hline Species & Methodology & Proteins & Interactions & Ref \\
\hline Cryptosporidium hominis & Integrated & 279 & 590 & {$[13]$} \\
\hline \multirow[t]{2}{*}{ Cryptosporidium parvum } & Integrated & 287 & 1,153 & [13] \\
\hline & Machine learning & 289 & 487 & {$[188]$} \\
\hline \multirow[t]{2}{*}{ Dictyostelium discoideum } & Integrated & 2,065 & 24,430 & {$[13]$} \\
\hline & Machine learning & 1,154 & 2,458 & {$[188]$} \\
\hline Dictyostelium purpureum & Integrated & 1,119 & 4,264 & {$[13]$} \\
\hline Entamoeba histolytica & Integrated & 641 & 1,402 & {$[13]$} \\
\hline Entamoeba dispar & Integrated & 616 & 1,273 & {$[13]$} \\
\hline Giardia lamblia & Integrated & 238 & 453 & {$[13]$} \\
\hline Leishmania arabica & Integrated & 1,356 & 5,262 & {$[292]$} \\
\hline \multirow[t]{5}{*}{ Leishmania braziliensis } & Structural, machine learning & 681 & 6,198 & {$[287]$} \\
\hline & Interolog & 7,950 & 39,420 & {$[288]$} \\
\hline & Integrated & 1,472 & 6,150 & {$[292]$} \\
\hline & Integrated & 735 & 2,490 & {$[13]$} \\
\hline & Machine learning & 321 & 621 & {$[188]$} \\
\hline Leishmania donovani & Integrated & 1,379 & 5,444 & {$[292]$} \\
\hline Leishmania enriettii & Integrated & 1,389 & 5981 & {$[292]$} \\
\hline \multirow[t]{5}{*}{ Leishmania infantum } & Structural, machine learning & 708 & 7,391 & {$[287]$} \\
\hline & Interolog & 7,823 & 45,235 & {$[288]$} \\
\hline & Integrated & 1,437 & 6657 & {$[292]$} \\
\hline & Integrated & 725 & 2,347 & {$[13]$} \\
\hline & Machine learning & 316 & 543 & {$[188]$} \\
\hline Leishmania major & Interolog, DDI & 1,366 & 33,861 & {$[295]$} \\
\hline
\end{tabular}


Table 5 - continued from previous page

\begin{tabular}{|c|c|c|c|c|}
\hline Species & Methodology & Proteins & Interactions & Ref \\
\hline & Interolog & 8,160 & 43,531 & {$[288]$} \\
\hline & Integrated & 1,477 & 7,227 & {$[292]$} \\
\hline & Machine learning & 367 & 642 & {$[188]$} \\
\hline & Integrated & 729 & 2,537 & {$[13]$} \\
\hline Leishmania mexicana & Integrated & 1,436 & 6,597 & {$[292]$} \\
\hline \multirow[t]{2}{*}{ Monosiga brevicollis } & Integrated & 839 & 2,840 & {$[13]$} \\
\hline & Machine learning & 621 & 933 & {$[188]$} \\
\hline Naegleria gruberi & Integrated & 1,102 & 4,471 & {$[13]$} \\
\hline Plasmodium berghei & Integrated & 428 & 1,056 & {$[13]$} \\
\hline Plasmodium chabaudi & Integrated & 422 & 1,035 & {$[13]$} \\
\hline \multirow[t]{7}{*}{ Plasmodium falciparum } & Interolog & 212 & 344 & {$[296]$} \\
\hline & Interolog, gene expression & 2,646 & 286,620 & {$[297]$} \\
\hline & PFIN & 3,667 & 388,969 & {$[293]$} \\
\hline & PFIN & 2,273 & 133,158 & {$[198]$} \\
\hline & Machine learning & 1,246 & 2,551 & {$[188]$} \\
\hline & Integrated & 1,688 & 4,634 & {$[13]$} \\
\hline & Interolog & - & 2,844 & {$[70]$} \\
\hline Plasmodium knowlesi & Integrated & 444 & 1,171 & {$[13]$} \\
\hline \multirow[t]{2}{*}{ Plasmodium vivax } & Interolog & - & 14,844 & {$[283]$} \\
\hline & Integrated & 426 & 1,212 & {$[13]$} \\
\hline Plasmodium yoelii & Integrated & 404 & 1,106 & {$[13]$} \\
\hline Paramecium tetraurelia & Integrated & 2,082 & 17,045 & {$[13]$} \\
\hline Tetrahymena thermophila & Integrated & 1,093 & 5,323 & {$[13]$} \\
\hline Theileria parva & Integrated & 334 & 793 & {$[13]$} \\
\hline Theileria annulata & Integrated & 365 & 857 & [13] \\
\hline Toxoplasma gondii & Integrated & 596 & 1,739 & {$[13]$} \\
\hline Trichomona vaginalis & Integrated & 813 & 2,611 & {$[13]$} \\
\hline \multirow[t]{2}{*}{ Trypanosoma brucei } & Integrated & 1,685 & 7,946 & {$[292]$} \\
\hline & Integrated & 708 & 3,494 & {$[13]$} \\
\hline Trypanosoma brucei gambiense & Integrated & 1,644 & 7,821 & {$[292]$} \\
\hline \multirow[t]{2}{*}{ Trypanosoma cruzi } & Integrated & 1,383 & 5,728 & {$[292]$} \\
\hline & Integrated & 1,267 & 5,258 & {$[13]$} \\
\hline Trypanosoma evansi & Integrated & 1,704 & 8,177 & {$[292]$} \\
\hline Trypanosoma vivax & Integrated & 1,519 & 6,688 & {$[292]$} \\
\hline Multiple species* & PFIN & 1,001 & 47,364 & {$[293]$} \\
\hline Multiple species** & Machine learning & 1,761 & 26,060 & {$[298]$} \\
\hline
\end{tabular}

\section{Mammals}

The laboratory mouse, Mus musculus, is possibly the most important model species that has been used extensively in the study of genetics [299]. Due to its importance to the understanding of human disease, the mouse interactome has been a key research goal since completion of the mouse genome, and a wealth of experimental [89, 300-308] and computational [13, 64, 188, 198, 309-312] 
interactome data have been produced, which along with human and yeast data, form the basis of interactome studies in many other mammals (Table 6).

One of the largest, MouseNet, represents a large-scale PFIN produced via machine learning based on multiple types of functional interaction data including PPIs, expression and phenotypes. This network successfully predicts known human disease phenotypes, demonstrating the potential of interactomes in cross-species prediction [64,313]. In a comparative analysis, Shin and colleagues found that differing ortholog mapping algorithms have low overlap, and so produced an interolog network that combined the different results [310]. Yellaboina and co-workers combined interolog mapping with genome context and phylogenetic profiles to produce a network of over 40,000 mouse interactions [309]. MppDB is a predicted mouse interactome built using text-mined data followed by machine learning using several data types and mapping techniques [311].

Many mammalian studies have concerned species with commercial value, for example Bos taurus interactomes were used to investigate meat production [314] and infection [315]. Wang and colleagues predicted interactomes for cattle, dogs, horses and rabbits and demonstrated their reliability using subcellular localisation and in comparison to randomised networks [316]. Of particular note is the evolutionary study of Zitnik and co-workers, who produced interactomes for 1,840 species, including 28 mammals. Interactomes were found to evolve to become more resilient to network failure, and in bacteria this resilience was correlated with the variability of the species' environment [13]. The FunCoup database contains PFINs for sixteen model species including four mammals, and provides an interactive interface for comparative interactomics between species [198]. The STRING database contains functional interaction data, including co-citation, co-expression and gene neighbourhood, for multiple species including several model mammals, which can be queried through an interactive server by protein name [317]. Finally, the BiomeNet server can be used to construct PFINs for any species based a set of eighteen PFINS including human and mouse [318].

Table 6: Computational interactomes in mammals. DDI: domain-domain interaction; PFIN: probabilistic functional integrated networks.

\begin{tabular}{llrrr} 
Species & Methodology & Proteins & Interactions & Ref \\
\hline Ailuropoda melanoleuca & Integrated & 5,034 & 41,328 & {$[13]$} \\
Bos taurus & Interolog, DDI & 17,291 & 447,014 & {$[316]$} \\
& Integrated & 8,615 & 276,128 & {$[13]$} \\
& Gene expression & 4,995 & $1,538,522$ & {$[319]$} \\
& Interolog & 330 & - & {$[314]$} \\
& Machine learning & 7,455 & 30,049 & {$[188]$} \\
& PFIN & 17,906 & $4,551,013$ & {$[198]$} \\
Callithrix jacchus & Integrated & 327 & 946 & {$[13]$} \\
Canis lupus familiaris & Interolog, DDI & 13,129 & 129,386 & {$[316]$} \\
& PFIN & 17,742 & $3,853,720$ & {$[198]$} \\
& Integrated & 7,923 & 166,025 & {$[13]$} \\
Cavia porcellus & Machine learning & 4,524 & 14,478 & {$[188]$} \\
& Integrated & 165 & 268 & {$[13]$} \\
Equus caballus & Machine learning & 129 & 155 & {$[188]$} \\
& Interolog, DDI & 10,689 & 93,414 & {$[316]$} \\
& Integrated & 5,395 & 45,074 & {$[13]$} \\
& Machine learning & 205 & 306 & {$[188]$} \\
\hline
\end{tabular}


Table 6 - continued from previous page

\begin{tabular}{llrrr} 
Species & Methodology & Proteins & Interactions & Ref \\
\hline Felis catus & Integrated & 5,285 & 44,325 & {$[13]$} \\
Gorilla gorilla & Integrated & 5,309 & 41,774 & {$[13]$} \\
Ictidomys tridecemlineatus & Integrated & 166 & 321 & {$[13]$} \\
Loxodonta africana & Integrated & 171 & 288 & {$[13]$} \\
Macaca mulatta & Integrated & 5,003 & 37,070 & {$[13]$} \\
& Machine learning & 205 & 234 & {$[188]$} \\
Microcebus murinus & Integrated & 64 & 121 & {$[13]$} \\
Monodelphis domestica & Integrated & 4,937 & 39,168 & {$[13]$} \\
Myotis lucifugus & Integrated & 140 & 262 & {$[13]$} \\
Mustela putorius furo & Integrated & 173 & 254 & {$[13]$} \\
Nomascus leucogenys & Integrated & 415 & 715 & {$[13]$} \\
Ornithorhynchus anatinus & Integrated & 3,817 & 26,941 & {$[13]$} \\
Oryctolagus cuniculus & Interolog, DDI & 12,586 & 115,296 & {$[316]$} \\
& Integrated & 292 & 844 & {$[13]$} \\
Otolemur garnettii & Integrated & 162 & 428 & {$[13]$} \\
Pan troglodytes & Integrated & 5,116 & 39,642 & {$[13]$} \\
& Machine learning & 195 & 228 & {$[188]$} \\
Pongo abelii & Integrated & 5,102 & 37,676 & {$[13]$} \\
& Machine learning & 919 & 1,563 & {$[188]$} \\
Procavia capensis & Integrated & 57 & 56 & {$[13]$} \\
Pteropus vampyrus & Integrated & 107 & 174 & {$[13]$} \\
Rattus norvegicus & Integrated & 13,897 & 305,939 & {$[320]$} \\
& Integrated & 9,439 & 261,737 & {$[13]$} \\
& Machine learning & 6,073 & 22,300 & {$[188]$} \\
Sarcophilus harrisii & PFIN & 18,322 & $5,560,189$ & {$[198]$} \\
Sus scrofa & Integrated & 5,004 & 40,001 & {$[13]$} \\
& Integrated & 8,201 & 143,516 & {$[13]$} \\
& Machine learning & 2,356 & 4,323 & {$[188]$} \\
Tursiop truncatus & Interolog, DDI & 11,955 & 567,441 & {$[321]$} \\
\hline \hline & Interolog & 9,534 & 204,699 & {$[322]$} \\
& Integrated & 110 & 163 & {$[13]$} \\
\hline
\end{tabular}

\section{Fish}

Zebrafish, Danio rerio, the best characterised of the fish, is a model for regeneration and development [323], and has been the subject of several experimental interactome studies [13, 188, 198, 324, 325]. Due to the economic importance of global fish production [326], many studies have aimed to understand the interactome of other fish (Table 7) and their responses to parasitic disease [210-212, 327-332].

Carrera and colleagues created an interactome from the STRING database based on the combined proteome of fifteen different sarcoplasmic fish, revealing a core interactome involved in energy and metabolism [333]. Millan-Cubillo and co-workers also used STRING to produce interaction networks for two developmental stages in the seabream, Sparus aurata, based on expression data [334]. A later 
seabream study used expression data to mine STRING for interactions of the stress response [335]. Co-expression analysis was also used to create a genetic interactome for the Nile tilapia, Oreochromis niloticus [336]. Zitnik and co-workers evolutionary study included seven fish and the coelocanth, Latimeria chalumnae [13].

Many interactome-based studies have been applied to understand the mechanisms of infection in fish. For instance, four related studies created host-pathogen interactomes between the parasites and fish species to investigate different aspects of infection: immune responses in gill tissues of the grouper [329]; interactions with host plasma proteins in carp [328]; interactions with liver cells in grouper [330]; and the blood immune response of the Japanese flounder [332]. Kumar and co-workers studied the immune response to Yersinia ruckeri infection in the rainbow trout, Oncorhynchus mykiss, using a combination of expression data and the STRING database [331]. Several studies have also investigated $C$. albicans infection in zebrafish using microarray data [210] and interolog mapping $[211,212]$ to decipher the zerbrafish immune response.

Table 7: Computational interactomes in Fish. *Gadus morhua, Merluccius australis australis, Lophius piscatorius, Genypterus blacodes,Brama brama,Diplodus sargus,Pagellus bogaraveo,Scomber japonicus,Sparus aurata, Thunnus albacares, Trachurus trachurus, Xiphias gladius, Lepidorhombus boscii, Solea solea, Salmo salar.

\begin{tabular}{llrrr} 
Species & Methodology & Proteins & Interactions & Reference \\
\hline Gasterosteus aculeatus & Integrated & 45 & 57 & {$[13]$} \\
Latimeria chalumnae & Integrated & 3,826 & 27,789 & {$[13]$} \\
Oreochromis niloticus & Integrated & 32 & 55 & {$[13]$} \\
Oryzias latipes & Integrated & 4,134 & 35,414 & {$[13]$} \\
Sparus aurata & Integrated & 18 & 61 & {$[335]$} \\
Takifugu rubripes & Integrated & 4,111 & 35,801 & {$[13]$} \\
Tetraodon nigroviridis & Integrated & 41 & 59 & {$[13]$} \\
& Machine learning & 142 & 203 & {$[188]$} \\
Xiphophorus maculatus & Integrated & 4,503 & 41,341 & {$[13]$} \\
Multiple species* & Integrated & 84 & 279 & {$[333]$} \\
\hline \hline
\end{tabular}

\section{Insects}

Drosphila melanogaster, the fruit fly, is the model insect and is widely used in genetic studies [337]. Several studies have been dedicated to understanding the interactome of this important species [13, 188, 198, 307, 338-355]. The Drosophila Interactions Database (DroID) [355, 356] and the Predicted Drosophila Interactome Resource (PDIR) are integrated database containing both experimental and predicted interactions [354]. Interactome analyses have been applied to the disease vectors Glossina morsitans morsitans (tsetse flies) [290, 291], Aedes aegypti [357-359] and Anopheles gambiae [13, 188] (mosquitos), and the pests Acyrthosiphon pisum (aphid) and Tribolium castaneum (flour beetle) [13]. The interactomes of several other insect species, such as the carpenter ant Camponotus floridanus [360], and the silk moth Bombyx mori [361] have also been investigated (Table 8).

\section{Nematodes and Platyhelminths}

The vast majority of experimental interactions for nematodes are for the model worm Caenorhabditis elegans [307, 353, 362-373]. C. elegans is a free-living nematode that was one of the first eukaryotes 
Table 8: Computational interactomes in Insects. DDI: domain-domain interactions; PFIN: probabilistic functional interaction network.

\begin{tabular}{llrrr} 
Species & Methodology & Proteins & Interactions & Reference \\
\hline Acyrthosiphon pisum & Integrated & 1,867 & 8,354 & {$[13]$} \\
Aedes aegypti & PFIN & 4,214 & 10,209 & {$[357]$} \\
& Machine learning & 1,310 & 2,396 & {$[188]$} \\
& Integrated & 1,994 & 8,913 & {$[13]$} \\
Anopheles gambiae & Machine learning & 1,537 & 3,442 & {$[188]$} \\
& Integrated & 1,808 & 7,214 & {$[13]$} \\
Apis mellifera & Integrated & 1,561 & 6,583 & {$[13]$} \\
Bombyx mori & Interolog & 4,623 & 7,736 & {$[361]$} \\
& Integrated & 1,732 & 8,512 & {$[13]$} \\
Camponotus floridanus & Interolog, DDI & 6,274 & 51,866 & {$[360]$} \\
Culex quinquefasciatus & Integrated & 1,846 & 8,800 & {$[13]$} \\
Drosophila ananassae & Integrated & 2,078 & 11,429 & {$[13]$} \\
Drosophila grimshawi & Integrated & 2,203 & 13,143 & {$[13]$} \\
Drosophila pseudoobscura & Machine learning & 1,461 & 2,650 & {$[188]$} \\
& Integrated & 2,111 & 11,062 & {$[13]$} \\
Drosophila virilis & Machine learning & 2,163 & 5,072 & {$[188]$} \\
& Integrated & 2,144 & 11,561 & {$[13]$} \\
Drosophila yakuba & Integrated & 2,119 & 11,268 & {$[13]$} \\
Drosophila willistoni & Integrated & 2,092 & 10,739 & {$[13]$} \\
Nasonia vitripennis & Machine learning & 2,175 & 5,261 & {$[188]$} \\
Pediculus humanus & Integrated & 1,397 & 4,805 & {$[13]$} \\
Tribolium castaneum & Integrated & 1,710 & 7,539 & {$[13]$} \\
\hline \hline
\end{tabular}

to have its genome sequenced [374], and considerable effort has been put into completing the interactome of this species [375], and in the comparison between its interactome and those of other model eukaryotes [307]. Several computationally-predicted interactomes have also been produced [13, 188, 198, 376-381].

$\mathrm{Li}$ and colleagues combined physical interaction data with interolog mapping to produce the Worm Interactome [376]. Simonis and co-workers extended this network using further Y2H screening to produce version 8 of the Worm Interactome [377]. By combining Y2H and protein-DNA interaction (PDI) mapping the C. elegans interactome was expanded to include more than 2000 transcription factor interactions [378]. Gunsalus and co-workers combined the Worm Interactome (version 5) [376] with expression and phenotypic data to produce an integrated network of early embryogenesis [379]. These datasets have formed the basis of many interactome analyses and comparisons in C. elegans and beyond [382, 383].

Few interactome studies have been carried out in other nematodes (Table 9) Interolog mapping was used to produce and compare host parasite interactomes for six parasites including the human and plant parasites Meloidogyne hapla and Meloidogyne incognita [384]. Comparison with a predicted interactome for $C$. elegans was then used to prioritise drug targets. Finally, Cuesta-Astroz and colleague's large-scale study of fifteen parasite-host interaction networks included an interactome network for Trichinella spiralis [294]. 
The platyhelminths Schistosoma mansoni and Schistosoma japonicum are important parasitic blood flukes that cause schistosomiasis in humans [385, 386]. Interolog mapping has been used to produce and compare host-parasite interactomes for six parasites including S. mansoni and S. japonicum [384]. White-Bear and colleagues used structural prediction, followed by extensive confidence filtering, to produce an interactome of over 1000 S. mansoni-human interactions [387]. A combination of Y2H and Co-IP produced 205 interactions involving the essential histone deacetylase 8 [388]. Co-IP was also used to identify the host-parasite interactome of $S$. mansoni and its mollusc host Biomphalaria glabrata [389]. In Cuesta-Astroz and colleague's large-scale study of fifteen parasitehost interaction networks, a network of $\sim 700$ interactions was produced for S. mansoni [294].

Castillo-Lara and co-workers used interolog mapping from a human reference interactome, gene expression data and machine learning to produce PlanNet, a predicted interactome for the planarian, Schmidtea mediterranea, with online visualisation and analysis tool [390]. This resource was later extended to allow exploration of the network using gene expression data [391]. Finally, a probabilisitic functional integrated network of interologs was produced for the mouse bile duct tapeworm, Hymenolepis microstoma [74]. Although there is little interactome data for these species (Table 9), interactomics has the potential to expand our understanding of parasitism in the future.

Table 9: Computational interactomes in Nematodes and Platyhelminths. PFIN: probabilistic functional interaction network. * Brugia malayi, Meloidogyne hapla, Meloidogyne incognita, Trichinella spiralis, Schistosoma mansoni and Schistosoma japonicum; networks combined to predict common drug target PPIs.

\begin{tabular}{llrrr} 
Species & Methodology & Proteins & Interactions & Reference \\
\hline Caenorhabditis briggsae & Machine learning & 474 & 699 & {$[188]$} \\
& Integrated & 1,547 & 6,558 & {$[13]$} \\
Caenorhabditis remanei & Machine learning & 1,312 & 2,225 & {$[188]$} \\
Trichinella spiralis & Integrated & 1,453 & 5,511 & {$[13]$} \\
\hline Hymenolepi microstoma & PFIN & 3,474 & 20,684 & {$[74]$} \\
Schistosoma mansoni & Integrated & 958 & 3,520 & {$[13]$} \\
Schmidtea mediterranea & Interolog, machine learning & - & 729,043 & {$[390]$} \\
Multiple* & Interolog & - & 8 & {$[384]$} \\
\hline \hline
\end{tabular}

\section{Other Eukaryotes}

Interactome analysis that have applied to a variety of other species, including birds, amphibians, reptiles and crustaceans, are summarised in Table 10.

Table 10: Computational interactomes in other eukaryotes. DDI: domain-domain interaction; PFIN: probabilistic functional interaction network.

\begin{tabular}{llrrr} 
Species & Methodology & Proteins & Interactions & Ref \\
\hline Birds & & & & \\
Gallus gallus & Interolog, DDI & 12,207 & 328,590 & {$[316]$} \\
& Interolog & 8,140 & 72,000 & {$[392]$} \\
& Integrated & 5,208 & 141886 & {$[13]$} \\
\hline
\end{tabular}


Table 10 - continued from previous page

\begin{tabular}{|c|c|c|c|c|}
\hline Species & Methodology & Proteins & Interactions & Ref \\
\hline & Machine learning & 4,542 & 14,244 & {$[188]$} \\
\hline & PFIN & 12,289 & $1,608,939$ & [198] \\
\hline Meleagris gallopavo & Integrated & 2,656 & 30,024 & {$[13]$} \\
\hline Taeniopygia guttata & Integrated & 6,105 & 227,682 & [13] \\
\hline \multicolumn{5}{|l|}{ Amphibians } \\
\hline \multirow[t]{2}{*}{ Xenopus tropicalis } & Integrated & 6,509 & 130,423 & {$[13]$} \\
\hline & Machine learning & 966 & 1,887 & [188] \\
\hline \multicolumn{5}{|l|}{ Reptiles } \\
\hline Pelodiscus sinensis & Integrated & 3,464 & 24,446 & {$[13]$} \\
\hline Anolis carolinensis & Integrated & 3,316 & 23,485 & {$[13]$} \\
\hline \multicolumn{5}{|l|}{ Molluscs } \\
\hline Theba pisana & DDI & 3,913 & 41,653 & {$[393]$} \\
\hline \multicolumn{5}{|l|}{ Crustaceans } \\
\hline Daphnia pulex & Machine leanring & 1,122 & 1,977 & [188] \\
\hline Eriocheir sinensis & Interolog & 3,223 & 35,787 & [394] \\
\hline \multirow[t]{3}{*}{ Litopenaeus vannamei } & Interolog & 4,858 & 104,187 & {$[395]$} \\
\hline & Gene expression, interolog & 127 & 1292 & {$[396]$} \\
\hline & Gene expression, interolog & 383 & 8,557 & {$[397]$} \\
\hline \multicolumn{5}{|l|}{ Arachnids } \\
\hline Stegodyphus mimosarum & Interolog & 3,810 & 58,489 & [398] \\
\hline \multirow[t]{2}{*}{ Ixodes scapularis } & Integrated & 2,052 & 12,610 & {$[13]$} \\
\hline & Machine learning & 749 & 1,103 & [188] \\
\hline \multicolumn{5}{|l|}{ Echinodermata } \\
\hline \multicolumn{5}{|l|}{ Cnidaria } \\
\hline \multirow[t]{2}{*}{ Nematostella vectensis } & Machine learning & 1,135 & 2,842 & [188] \\
\hline & Integrated & 1,621 & 7,487 & {$[13]$} \\
\hline \multicolumn{5}{|l|}{ Heterokonta } \\
\hline Phaeodactylum tricornutum & Integrated & 980 & 4,057 & [13] \\
\hline Phytophthora infestans & Integrated & 1,507 & 8,803 & {$[13]$} \\
\hline Thalassiosira pseudonana & Integrated & 1,053 & 4,739 & {$[13]$} \\
\hline \multicolumn{5}{|l|}{ Rhodophyta } \\
\hline \multicolumn{5}{|l|}{ Placozoa } \\
\hline \multirow[t]{2}{*}{ Trichoplax adhaerens } & Integrated & 1,353 & 5,610 & {$[13]$} \\
\hline & Machine learning & 1,022 & 1,688 & [188] \\
\hline \multicolumn{5}{|l|}{ Porifera } \\
\hline Amphimedon queenslandica & Integrated & 1,487 & 6,853 & {$[13]$} \\
\hline \multicolumn{5}{|l|}{ Cephalochordata } \\
\hline \multirow[t]{2}{*}{ Branchiostoma floridae } & Integrated & 3,015 & 31,607 & {$[13]$} \\
\hline & Machine learning & 1,481 & 4,143 & [188] \\
\hline \multicolumn{5}{|l|}{ Tunicata } \\
\hline \multirow[t]{2}{*}{ Ciona intestinalis } & Integrated & 1,372 & 5,432 & {$[13]$} \\
\hline & PFIN & 6,098 & $1,373,106$ & [198] \\
\hline Ostreococcus lucimarinus & Machine learning & 576 & 946 & [188] \\
\hline
\end{tabular}


Table 10 - continued from previous page Species Methodology

Proteins Interactions Ref




\section{Future Perspective}

Data from traditional model organisms, chosen in part for ease of their experimental study [399], are now being expanded by the addition of genomic data from closely-related species [400]. Diverse organisms have become the study species of choice for answering more obscure biological questions [401] and to test the long-held fundamental rules built from the original model species [402]. Comparative interactomics is now possible on a large scale as demonstrated by Zitnik and colleagues study of 1,840 predicted interactomes spanning the tree of life [13]. With over 8 million proteinprotein interactions, this dataset allowed the authors to observe interaction rewiring that had only previously been seen on a smaller scale [191-193, 353, 378, 403].

Computationally-predicted interactions can compensate for the lack of experimental data in many species but, like experimental methods, they have drawbacks such as noise and false positive interactions [293, 404]. Conservation of PPI is unequal and accuracy of interolog mapping will vary between species [405]. This accuracy will also be dependent on evolutionary distance and careful selection of thresholds will be necessary [406]. It's clear from yeast interactomes that there can be low overlap between species; $S$. cerevsiae is well characterised but the C. albicans and S. pombe interactomes are different in a number of respects [191, 193, 204, 407]. Combining different computational methods $[86,105,106,310]$, and experimental data if available $[232,235,376,408]$, can give a fuller picture of the interactome and mitigate the effect of data noise by using a probabilistic framework [74, 198].

Interolog and DDI mapping can only detect interactions within conserved sequences or domains [68]; organism-specific proteins and interactions are missed. Filling in the gaps is vital to our understanding of biology and evolution. Interactome analyses can help to identify these gaps and target further analysis in non-model species. While there are parts of some interactomes that cannot currently be predicted, interactome accuracy will improve as coverage of diverse species increases. Non-model species have already been used to provide insights in a number of fields, including human disease [409], ageing and regeneration [410, 411], and to expand our understanding of evolution [412], ecology [413, 414] and biological diversity [415, 416]. There are currently more than 13,000 entries from over 10,000 species in the NCBI Genome database ${ }^{1}$, the majority of which are non-models. At the same time, de novo transcriptomes have also been produced for many species that lack genome sequence data [417-420]. The Sequence Read archive contains more than 20,000 non-model transcriptomic datasets from over 7,000 species $^{1}$. These resources represent a huge amount of data for interactome generation in more diverse species and provide the basis to build interactomes that will potentially have impact across the field of Biology.

\section{References}

[1] A H Tong, M Evangelista, A B Parsons, H Xu, et al. Systematic genetic analysis with ordered arrays of yeast deletion mutants. Science 294 (2001), pp. 2364-2368.

[2] X Pan, D S Yuan, D Xiang, X Wang, et al. A robust toolkit for functional profiling of the yeast genome. Mol Cell 16 (2004), pp. 487-496.

[3] M Schuldiner, S R Collins, N J Thompson, V Denic, et al. Exploration of the function and organization of the yeast early secretory pathway through an epistatic miniarray profile. Cell 123 (2005), pp. 507-519.

\footnotetext{
${ }^{1}$ January 2021
} 
[4] T Ito, T Chiba, R Ozawa, M Yoshida, et al. A comprehensive two-hybrid analysis to explore the yeast protein interactome. Proc Natl Acad Sci USA 98 (2001), pp. 4569-4574.

[5] P Uetz, L Giot, G Cagney, T A Mansfield, et al. A comprehensive analysis of protein-protein interactions in Saccharomyces cerevisiae. Nature 403 (2000), pp. 623-627.

[6] A C Gavin, P Aloy, P Grandi, R Krause, et al. Proteome survey reveals modularity of the yeast cell machinery. Nature 440 (2006), pp. 631-636.

[7] N J Krogan, G Cagney, H Yu, G Zhong, et al. Global landscape of protein complexes in the yeast Saccharomyces cerevisiae. Nature 440 (2006), pp. 637-643.

[8] R Yu and J Nielsen. Big data in yeast systems biology. FEMS Yeast Res 19 (2019), foz070.

[9] L Loewe. A framework for evolutionary systems biology. BMC Syst Biol 3 (2009), p. 27.

[10] T Ideker, T Galitski, and L Hood. A new approach to decoding life: systems biology. Annu Rev Genomics Hum Genet 2 (2001), pp. 343-372.

[11] A-L Barabási and Z N Oltvai. Network biology: understanding the cell's functional organization. Nat Rev Genet 5 (2004), pp. 101-113.

[12] E V Koonin and Y I Wolf. Evolutionary systems biology: links between gene evolution and function. Curr Opin Biotechnol 17 (2006), pp. 481-487.

[13] M Zitnik, R Sosič, M W Feldman, and J Leskovec. Evolution of resilience in protein interactomes across the tree of life. Proc Natl Acad Sci U S A 116 (2019), pp. 4426-4433.

[14] T Lemberger. Systems biology in human health and disease. Mol Syst Biol 3 (2007), p. 136.

[15] H Kitano. Systems biology: a brief overview. Science 295 (2002), pp. 1662-1664.

[16] M E Cusick, N Klitgord, M Vidal, and D E Hill. Interactome: gateway into systems biology. Hum Mol Genet 14 Spec No. 2 (2005), pp. 171-181.

[17] J Goll and P Uetz. The elusive yeast interactome. Genome Biol 7 (2006), p. 223.

[18] S H Yook, Z N Oltvai, and A-L Barabási. Functional and topological characterization of protein interaction networks. Proteomics 4 (2004), pp. 928-942.

[19] L H Hartwell, J J Hopfield, S Leibler, and A W Murray. From molecular to modular cell biology. Nature 402 (1999), pp. C47-C52.

[20] D Eisenberg, E M Marcotte, I. Xenarios, and T. O. Yeates. Protein function in the postgenomic era. Nature 405 (2000), pp. 823-826.

[21] M Brehme and M Vidal. A global protein-lipid interactome map. Mol Syst Biol 6 (2010), p. 443 .

[22] A Trewavas. A brief history of systems biology. Plant Cell 18 (2006), pp. 2420-2430.

[23] I Lee, S V Date, A T Adai, and E M Marcotte. A probabilistic functional network of yeast genes. Science 306 (2004), pp. 1555-1558.

[24] I Lee, Z Li, and E M Marcotte. An improved, bias-reduced probabilistic functional gene network of baker's yeast, Saccharomyces cerevisiae. PloS One 2 (2007), e988.

[25] K James, A Wipat, and J Hallinan. Integration of full-coverage probabilistic functional networks with relevance to specific biological processes. Data Integr Life Sci 5647 (2009), pp. 3146.

[26] W Huber, V J Carey, L Long, S Falcon, et al. Graphs in molecular biology. BMC Bioinformatics 8 (2007), S8. 
[27] G C K W Koh, P Porras, B Aranda, H Hermjakob, et al. Analyzing protein-protein interaction networks. J Proteome Res 11 (2012), pp. 2014-2031.

[28] O Mason and M Verwoerd. Graph theory and networks in Biology. IET Syst Biol 1 (2007), pp. 89-119.

[29] D Bu, Y Zhao, L Cai, H Xue, et al. Topological structure analysis of the protein-protein interaction network in budding yeast. Nucleic Acids Res 31 (2003), pp. 2443-2450.

[30] H Jeong, S P Mason, A L Barabási, and Z N Oltvai. Lethality and centrality in protein networks. Nature 411 (2001), pp. 41-42.

[31] S Wuchty, Z N Oltvai, and A L Barabási. Evolutionary conservation of motif constituents in the yeast protein interaction network. Nat Genet 35 (2003), pp. 176-179.

[32] S Asthana, O D King, F D Gibbons, and F P Roth. Predicting protein complex membership using probabilistic network reliability. Genome Res 14 (2004), pp. 1170-1175.

[33] G T Hart, I Lee, and E R Marcotte. A high-accuracy consensus map of yeast protein complexes reveals modular nature of gene essentiality. BMC Bioinformatics 8 (2007), p. 236.

[34] L Ou-Yang, X-F Zhang, D-Q Dai, M-Y Wu, et al. Protein complex detection based on partially shared multi-view clustering. BMC Bioinformatics 17 (2016), p. 371.

[35] D Piovesan, M Giollo, E Leonardi, C Ferrari, et al. INGA: protein function prediction combining interaction networks, domain assignments and sequence similarity. Nucleic Acids Res 43 (2015), W134-W140.

[36] H N Chua, W K Sung, and L Wong. Using indirect protein interactions for the prediction of Gene Ontology functions. BMC Bioinformatics 8 (2007), S8.

[37] U Karaoz, T M Murali, S Letovsky, Y Zheng, et al. Whole-genome annotation by using evidence integration in functional-linkage networks. Proc Natl Acad Sci U S A 101 (2004), pp. 2888-2893.

[38] C S Goh and F E Cohen. Co-evolutionary analysis reveals insights into protein-protein interactions. J Mol Biol 324 (2002), pp. 177-192.

[39] H B Fraser, A E Hirsh, L M Steinmetz, C Scharfe, et al. Evolutionary rate in the protein interaction network. Science 296 (2002), pp. 750-752.

[40] B P Kelley, R Sharan, R M Karp, T Sittler, et al. Conserved pathways within bacteria and yeast as revealed by global protein network alignment. Proc Natl Acad Sci U S A 100 (2003), pp. 11394-11399.

[41] M Jafari, M Sadeghi, M Mirzaie, S-A Marashi, et al. Evolutionarily conserved motifs and modules in mitochondrial protein-protein interaction networks. Mitochondrion 13 (2013), pp. $668-675$.

[42] A Clauset, C Moore, and M E Newman. Hierarchical structure and the prediction of missing links in networks. Nature 453 (2008), pp. 98-101.

[43] I A Kovács, K Luck, K Spirohn, Y Wang, et al. Network-based prediction of protein interactions. Nat Commun 10 (2019), p. 1240.

[44] E Franzosa, B Linghu, and Y Xia. Computational reconstruction of protein-protein interaction networks: algorithms and issues. Methods Mol Biol 541 (2009), pp. 89-100.

[45] M Fromont-Racine, J C Rain, and P Legrain. Toward a functional analysis of the yeast genome through exhaustive two-hybrid screens. Nat Genet 16 (1997), pp. 277-282. 
[46] A C Gavin, M Bosche, R Krause, P Grandi, et al. Functional organization of the yeast proteome by systematic analysis of protein complexes. Nature 415 (2002), pp. 141-147.

[47] Y Ho, A Gruhler, A Heilbut, G D Bader, et al. Systematic identification of protein complexes in Saccharomyces cerevisiae by mass spectrometry. Nature 415 (2002), pp. 180-183.

[48] J F Rual, K Venkatesan, T Hao, T Hirozane-Kishikawa, et al. Towards a proteome-scale map of the human protein-protein interaction network. Nature 437 (2005), pp. 1173-1178.

[49] U Stelzl, U Worm, M Lalowski, C Haenig, et al. A human protein-protein interaction network: a resource for annotating the proteome. Cell 122 (2005), pp. 957-968.

[50] R M Ewing, P Chu, F Elisma, H Li, et al. Large-scale mapping of human protein-protein interactions by mass spectrometry. Mol Syst Biol 3 (2007), p. 89.

[51] H Yu, P Braun, M A Yildirim, I Lemmens, et al. High-quality binary protein interaction map of the yeast interactome network. Science 322 (2008), pp. 104-110.

[52] C Lee. Coimmunoprecipitation assay. Methods Mol Biol 362 (2007), pp. 401-406.

[53] S Pang C N Iand Ballouz, D Weissberger, L M Thibaut, J J Hamey, et al. Analytical guidelines for co-fractionation mass spectrometry obtained through global profiling of gold standard Saccharomyces cerevisiae protein complexes. Mol Cell Proteomics 19 (2020), pp. 1876-1895.

[54] X Tang and J E. Bruce. Chemical cross-linking for protein-protein interaction studies. Methods Mol Biol 492 (2009), pp. 283-293.

[55] S Mohr, C Bakal, and N Perrimon. Genomic screening with RNAi: results and challenges. Annu Rev Biochem 79 (2010), pp. 37-64.

[56] A Beyer, S Bandyopadhyay, and T Ideker. Integrating physical and genetic maps: from genomes to interaction networks. Nat Rev Genet 8 (2007), pp. 699-710.

[57] S J Dixon, Y Fedyshyn, J L Y Koh, T S K Prasad, et al. Significant conservation of synthetic lethal genetic interaction networks between distantly related eukaryotes. Proc Natl Acad Sci U S A 105 (2008), pp. 16653-16658.

[58] C von Mering, E M Zdobnov, S Tsoka, F D Ciccarelli, et al. Genome evolution reveals biochemical networks and functional modules. Proc Natl Acad Sci U S A 100 (2003), pp. 1542815433.

[59] R Sharan and T Ideker. Modeling cellular machinery through biological network comparison. Nat Biotechnol 24 (2006), pp. 427-433.

[60] D Banky, R Ordog, and V Grolmusz. NASCENT: an automatic protein interaction network generation tool for non-model organisms. Bioinformation 3 (2009), pp. 361-363.

[61] F He, Y Zhang, H Chen, Z Zhang, et al. The prediction of protein-protein interaction networks in rice blast fungus. BMC Genomics 9 (2008), p. 519.

[62] X He and J Zhang. Higher duplicability of less important genes in yeast genomes. Mol Biol Evol 23 (2006), pp. 144-151.

[63] T A Boltz, P Devkota, and S Wuchty. Collective influencers in protein interaction networks. Sci Rep 9 (2019), p. 3948.

[64] E Kim, S Hwang, H Kim, H Shim, et al. MouseNet v2: a database of gene networks for studying the laboratory mouse and eight other model vertebrates. Nucleic Acids Res 44 (2016), pp. D848-D854. 
[65] S Wuchty, A-L Barabási, and M T Ferdig. Stable evolutionary signal in a yeast protein interaction network. BMC Evol Biol 6 (2006), p. 8.

[66] A N Nguyen Ba, B J Yeh, D van Dyk, A R Davidson, et al. Proteome-wide discovery of evolutionary conserved sequences in disordered regions. Sci Signal 5 (2012), rs1.

[67] B Snel, V van Noort, and M A Huynen. Gene co-regulation is highly conserved in the evolution of eukaryotes and prokaryotes. Nucleic Acids Res 32 (2004), pp. 4725-4731.

[68] L R Matthews, P Vaglio, J Reboul, H Ge, et al. Identification of potential interaction networks using sequence-based searches for conserved protein-protein interactions or "interologs". Genome Res 11 (2001), pp. 2120-2126.

[69] H Yu, N M Luscombe, H X Lu, X Zhu, et al. Annotation transfer between genomes: proteinprotein interologs and protein-DNA regulogs. Genome Res 14 (2004), pp. 1107-1118.

[70] S-A Lee, C-H Chan, C-H Tsai, J-M Lai, et al. Ortholog-based protein-protein interaction prediction and its application to inter-species interactions. BMC Bioinformatics 9 Suppl 12 (2008), S11.

[71] M Michaut, S Kerrien, L Montecchi-Palazzi, F Chauvat, et al. InteroPorc: automated inference of highly conserved protein interaction networks. Bioinformatics 24 (2008), pp. 16251631.

[72] T W Huang, A C Tien, W S Huang, Y C Lee, et al. POINT: a database for the prediction of protein-protein interactions based on the orthologous interactome. Bioinformatics 20 (2004), pp. 3273-3276.

[73] A M Wiles, M Doderer, J Ruan, T-T Gu, et al. Building and analyzing protein interactome networks by cross-species comparisons. BMC Syst Biol 4 (2010), p. 36.

[74] K James and P D Olson. The tapeworm interactome: inferring confidence scored proteinprotein interactions from the proteome of Hymenolepis microstoma. BMC Genomics 21 (2020), p. 346.

[75] J M Stuart, E Segal, D Koller, and S K Kim. A gene-coexpression network for global discovery of conserved genetic modules. Science 302 (2003), pp. 249-255.

[76] P Tsaparas, L Mariño-Ramírez, O Bodenreider, E V Koonin, et al. Global similarity and local divergence in human and mouse gene co-expression networks. BMC Evol Biol 6 (2006), p. 70 .

[77] V van Noort, B Snel, and M A Huynen. Predicting gene function by conserved co-expression. Trends Genet 19 (2003), pp. 238-242.

[78] J Park, M Lappe, and S A Teichmann. Mapping protein family interactions: intramolecular and intermolecular protein family interaction repertoires in the PDB and yeast. $J$ Mol Biol 307 (2001), pp. 929-938.

[79] M Deng, S Mehta, F Sun, and T Chen. Inferring domain-domain interactions from proteinprotein interactions. Genome Res 12 (2002), pp. 1540-1548.

[80] T Doerks, R R Copley, J Schultz, C P Ponting, et al. Systematic identification of novel protein domain families associated with nuclear functions. Genome Res 12 (2002), pp. 47-56.

[81] E Sprinzak and H Margalit. Correlated sequence-signatures as markers of protein-protein interaction. J Mol Biol 311 (2001), pp. 681-692.

[82] S-K Ng, Z Zhang, and S-H Tan. Integrative approach for computationally inferring protein domain interactions. Bioinformatics 19 (2003), pp. 923-929. 
[83] X W Chen, M Liu, and R Ward. Protein function assignment through mining cross-species protein-protein interactions. PLoS One 3 (2008), e1562.

[84] C Chen, J-F Zhao, Q Huang, R-S Wang, et al. Inferring domain-domain interactions from protein-protein interactions in the complex network conformation. BMC Syst Biol 6 Suppl 1 (2012), S7.

[85] J R Bock and D A Gough. Predicting protein-protein interactions from primary structure. Bioinformatics 17 (2001), pp. 455-460.

[86] D Betel, K E Breitkreuz, R Isserlin, D Dewar-Darch, et al. Structure-templated predictions of novel protein interactions from sequence information. PLoS Comput Biol 3 (2007), pp. 17831789.

[87] R D Finn, B L Miller, J Clements, and A Bateman. iPfam: a database of protein family and domain interactions found in the Protein Data Bank. Nucleic Acids Res 42 (2014), pp. D364D373.

[88] X-M Zhao, X-W Zhang, W-H Tang, and L Chen. FPPI: Fusarium graminearum proteinprotein interaction database. J Proteome Res 8 (2009), pp. 4714-4721.

[89] K Zhang, Y Li, T Li, Z-G Li, et al. Pathogenicity genes in Ustilaginoidea virens revealed by a predicted protein-protein interaction network. J Proteome Res 16 (2017), pp. 1193-1206.

[90] T Huo, W Liu, Y Guo, C Yang, et al. Prediction of host - pathogen protein interactions between Mycobacterium tuberculosis and Homo sapiens using sequence motifs. BMC Bioinformatics 16 (2015), p. 100.

[91] D Lei, R Lin, P Yin Cand Li, and A Zheng. Global protein-protein interaction network of rice sheath blight pathogen. J Proteome Res 13 (2014), pp. 3277-3293.

[92] G Singh, V Singh, and V Singh. Genome-wide interologous interactome map (TeaGPIN) of Camellia sinensis. Genomics S0888-7543 (2020), pp. 30452-30455.

[93] O Dror, D Schneidman-Duhovny, A Shulman-Peleg, R Nussinov, et al. Structural similarity of genetically interacting proteins. BMC Syst Biol 2 (2008), p. 69.

[94] P Aloy and R B Russell. Interrogating protein interaction networks through structural biology. Proc Natl Acad Sci US A 99 (2002), pp. 5896-5901.

[95] J Janin, K Henrick, J Moult, L T Eyck, et al. CAPRI: a Critical Assessment of PRedicted Interactions. Proteins 52 (2003), pp. 2-9.

[96] L Lu, A K Arakaki, H Lu, and J Skolnick. Multimeric threading-based prediction of proteinprotein interactions on a genomic scale: application to the Saccharomyces cerevisiae proteome. Genome Res 13 (2003), pp. 1146-1154.

[97] P Aloy and R B Russell. InterPreTS: protein interaction prediction through tertiary structure. Bioinformatics 19 (2003), pp. 161-162.

[98] M Hue, M Riffle, J P Vert, and W S Noble. Large-scale prediction of protein-protein interactions from structures. BMC Bioinformatics 11 (2010), p. 144.

[99] L Lu, H Lu, and J Skolnick. MULTIPROSPECTOR: an algorithm for the prediction of protein-protein interactions by multimeric threading. Proteins 49 (2002), pp. 350-364.

[100] G R Smith and M J Sternberg. Prediction of protein-protein interactions by docking methods. Curr Opin Struct Biol 12 (2002), pp. 28-35.

[101] U Ogmen, O Keskin, A S Aytuna, R Nussinov, et al. PRISM: protein interactions by structural matching. Nucleic Acids Res 33 (2005), W331-W336. 
[102] P Aloy, B Böttcher, H Ceulemans, C Leutwein, et al. Structure-based assembly of protein complexes in yeast. Science 303 (2004), pp. 2026-2029.

[103] M Ohue, Y Matsuzaki, T Shimoda, T Ishida, et al. Highly precise protein-protein interaction prediction based on consensus between template-based and de novo docking methods. $B M C$ Proc 7 (2013), S6.

[104] Y-S Lo, Y-C Chen, and J-M Yang. 3D-interologs: an evolution database of physical proteinprotein interactions across multiple genomes. BMC Genomics 11 Suppl 3 (2010), S7.

[105] A S Aytuna, A Gursoy, and O Keskin. Prediction of protein-protein interactions by combining structure and sequence conservation in protein interfaces. Bioinformatics 21 (2005), pp. 28502855 .

[106] S Gong, G Yoon, I Jang, D Bolser, et al. PSIbase: a database of protein structural interactome map (PSIMAP). Bioinformatics 21 (2005), pp. 2541-2543.

[107] F Pazos and A Valencia. In silico two-hybrid system for the selection of physically interacting protein pairs. Proteins 47 (2002), pp. 219-227.

[108] L Skrabanek, H K Saini, G D Bader, and A J Enright. Computational prediction of proteinprotein interactions. Mol Biotechnol 38 (2008), pp. 1-17.

[109] T Dandekar, B Snel, M Huynen, and P Bork. Conservation of gene order: a fingerprint of proteins that physically interact. Trends Biochem Sci 23 (1998), pp. 324-328.

[110] P M Bowers, M Pellegrini, M J Thompson, J Fierro, et al. Prolinks: a database of protein functional linkages derived from coevolution. Genome Biol 5 (2004), R35.

[111] R Overbeek, M Fonstein, M D'Souza, G D Pusch, et al. The use of gene clusters to infer functional coupling. Proc Natl Acad Sci U S A 96 (1999), pp. 2896-2901.

[112] M Huynen, B Snel, W Lathe, and P Bork. Predicting protein function by genomic context: quantitative evaluation and qualitative inferences. Genome Res 10 (2000), pp. 1204-1210.

[113] I K Kirk, N Weinhold, S Brunak, and K Belling. The impact of the protein interactome on the syntenic structure of mammalian genomes. PloS One 12 (2017), e0179112.

[114] E M Marcotte, M Pellegrini, H L Ng, D W Rice, et al. Detecting protein function and proteinprotein interactions from genome sequences. Science 285 (1999), pp. 751-753.

[115] A J Enright, I Iliopoulos, N C Kyrpides, and C A Ouzounis. Protein interaction maps for complete genomes based on gene fusion events. Nature 402 (1999), pp. 86-90.

[116] I Yanai, A Derti, and C DeLisi. Genes linked by fusion events are generally of the same functional category: a systematic analysis of 30 microbial genomes. Proc Natl Acad Sci U S A 98 (2001), pp. 7940-7945.

[117] F Pazos, J A Ranea, D Juan, and M J Sternberg. Assessing protein co-evolution in the context of the tree of life assists in the prediction of the interactome. J Mol Biol 352 (2005), pp. 1002-1015.

[118] J Wu, S Kasif, and C DeLisi. Identification of functional links between genes using phylogenetic profiles. Bioinformatics 19 (2003), pp. 1524-1530.

[119] Y I Wolf, I B Rogozin, A S Kondrashov, and E V Koonin. Genome alignment, evolution of prokaryotic genome organization, and prediction of gene function using genomic context. Genome Res 11 (2001), pp. 356-372. 
[120] J Sun, Y Li, and Z Zhao. Phylogenetic profiles for the prediction of protein-protein interactions: how to select reference organisms? Biochem Biophys Res Commun 353 (2007), pp. 985991.

[121] J Sun and Z Zhao. Construction of phylogenetic profiles based on the genetic distance of hundreds of genomes. Biochem Biophys Res Commun 355 (2007), pp. 849-853.

[122] R Jothi, M G Kann, and T M Przytycka. Predicting protein-protein interaction by searching evolutionary tree automorphism space. Bioinformatics 21 Suppl 1 (2005), pp. i241-i250.

[123] T Gaasterland and M A Ragan. Microbial genescapes: phyletic and functional patterns of ORF distribution among prokaryotes. Microb Comp Genomics 3 (1998), pp. 199-217.

[124] M Pellegrini, E M Marcotte, M J Thompson, D Eisenberg, et al. Assigning protein functions by comparative genome analysis: protein phylogenetic profiles. Proc Natl Acad Sci USA 96 (1999), pp. 4285-4288.

[125] F Pazos and A Valencia. Similarity of phylogenetic trees as indicator of protein-protein interaction. Protein Eng 14 (2001), pp. 609-614.

[126] D Juan, F Pazos, and A Valencia. High-confidence prediction of global interactomes based on genome-wide coevolutionary networks. Proc Natl Acad Sci U S A 105 (2008), pp. 934-939.

[127] T Sato, Y Yamanishi, M Kanehisa, and H Toh. The inference of protein-protein interactions by co-evolutionary analysis is improved by excluding the information about the phylogenetic relationships. Bioinformatics 21 (2005), pp. 3482-3489.

[128] G D Bader and C W Hogue. Analyzing yeast protein-protein interaction data obtained from different sources. Nat Biotechnol 20 (2002), pp. 991-997.

[129] S R Collins, P Kemmeren, X C Zhao, J F Greenblatt, et al. Toward a comprehensive atlas of the physical interactome of Saccharomyces cerevisiae. Mol Cell Proteomics 6 (2007), pp. 439450 .

[130] M E Futschik, G Chaurasia, and H Herzel. Comparison of human protein-protein interaction maps. Bioinformatics 23 (2007), pp. 605-611.

[131] A H Tong, G Lesage, G D Bader, H Ding, et al. Global mapping of the yeast genetic interaction network. Science 303 (2004), pp. 808-813.

[132] C Huttenhower and O G Troyanskaya. Assessing the functional structure of genomic data. Bioinformatics 24 (2008), pp. 330-338.

[133] M Morsy, S Gouthu, S Orchard, D Thorneycroft, et al. Charting plant interactomes: possibilities and challenges. Trends Plant Sci 13 (2008), pp. 183-191.

[134] A R Joyce and B Ø Palsson. The model organism as a system: integrating 'omics' data sets. Nat Rev Mol Cell Biol 7 (2006), pp. 198-210.

[135] E Marcotte and S Date. Exploiting big biology: integrating large-scale biological data for function inference. Brief Bioinform 2 (2001), pp. 363-374.

[136] M A Gilchrist, L A Salter, and A Wagner. A statistical framework for combining and interpreting proteomic datasets. Bioinformatics 20 (2004), pp. 689-700.

[137] D Scholtens, M Vidal, and R Gentleman. Local modeling of global interactome networks. Bioinformatics 21 (2005), pp. 3548-3557.

[138] H Ge, A J M Walhout, and M Vidal. Integrating 'omic' information: a bridge between genomics and systems biology. Trends Genet 19 (2003), pp. 551-560. 
[139] E V Koonin. Systemic determinants of gene evolution and function. Mol Syst Biol 1 (2005), p. 2005.0021.

[140] A Kumar, S Agarwal, J A Heyman, S Matson, et al. Subcellular localization of the yeast proteome. Genes Dev 16 (2002), pp. 707-719.

[141] W K Huh, J V Falvo, L C Gerke, A S Carroll, et al. Global analysis of protein localization in budding yeast. Nature 425 (2003), pp. 686-691.

[142] G R Mishra, M Suresh, K Kumaran, N Kannabiran, et al. Human protein reference database2006 update. Nucleic Acids Res 34 (Database issue) (2006), pp. 411-414.

[143] N Daraselia, A Yuryev, S Egorov, S Novichkova, et al. Extracting human protein interactions from MEDLINE using a full-sentence parser. Bioinformatics 20 (2004), pp. 604-611.

[144] H M Müller, E E Kenny, and P W Sternberg. Textpresso: an ontology-based information retrieval and extraction system for biological literature. PLoS Biol 2 (2004), e309.

[145] A K Ramani, R C Bunescu, R J Mooney, and E M Marcotte. Consolidating the set of known human protein-protein interactions in preparation for large-scale mapping of the human interactome. Genome Biol 6 (2005), R40.

[146] Y Chen and D Xu. Global protein function annotation through mining genome-scale data in yeast Saccharomyces cerevisiae. Nucleic Acids Res 32 (2004), pp. 6414-6424.

[147] L Kiemer, S Costa, M Ueffing, and G Cesareni. WI-PHI: a weighted yeast interactome enriched for direct physical interactions. Proteomics 7 (2007), pp. 932-943.

[148] M G Kann. Protein interactions and disease: computational approaches to uncover the etiology of diseases. Brief Bioinform 8 (2007), pp. 333-346.

[149] J Geisler-Lee, N O'Toole, R Ammar, N J Provart, et al. A predicted interactome for Arabidopsis. Plant Physiol (2007), pp. 317-329.

[150] Y Liu, I Kim, and H Zhao. Protein interaction predictions from diverse sources. Drug Discov Today 13 (2008), pp. 409-416.

[151] F Ramírez, A Schlicker, Y Assenov, T Lengauer, et al. Computational analysis of human protein interaction networks. Proteomics 7 (2007), pp. 2541-2552.

[152] I Yanai and C DeLisi. The society of genes: networks of functional links between genes from comparative genomics. Genome Biol 3 (2002), research0064.

[153] E M Marcotte, M Pellegrini, M J Thompson, T O Yeates, et al. A combined algorithm for genome-wide prediction of protein function. Nature 402 (1999), pp. 83-86.

[154] E Sprinzak, S Sattath, and H Margalit. How reliable are experimental protein-protein interaction data? J Mol Biol 327 (2003), pp. 919-923.

[155] J C Mellor, I Yanai, K H Clodfelter, J Mintseris, et al. Predictome: a database of putative functional links between proteins. Nucleic Acids Res 30 (2002), pp. 306-309.

[156] A Patil and H Nakamura. Filtering high-throughput protein-protein interaction data using a combination of genomic features. BMC Bioinformatics 6 (2005), p. 100.

[157] M Gerstein, N Lan, and R Jansen. Integrating interactomes. Science 295 (2002), pp. $284-287$.

[158] R Jansen, N Lan, J Qian, and M Gerstein. Integration of genomic datasets to predict protein complexes in yeast. J Struct Funct Genomics 2 (2002), pp. 71-81.

[159] B Titz, M Schlesner, and P Uetz. What do we learn from high-throughput protein interaction data? Expert Rev Proteomics 1 (2004), pp. 111-121. 
[160] C von Mering, R Krause, B Snel, M Cornell, et al. Comparative assessment of large-scale data sets of protein-protein interactions. Nature 417 (2002), pp. 399-403.

[161] J D Han, N Bertin, T Hao, D S Goldberg, et al. Evidence for dynamically organized modularity in the yeast protein-protein interaction network. Nature 430 (2004), pp. 88-93.

[162] M R Said, T J Begley, A V Oppenheim, D A Lauffenburger, et al. Global network analysis of phenotypic effects: protein networks and toxicity modulation in Saccharomyces cerevisiae. Proc Natl Acad Sci US A 101 (2004), pp. 18006-18011.

[163] A G Fraser and E M Marcotte. A probabilistic view of gene function. Nat Genet 36 (2004), pp. 559-564.

[164] S Suthram, T Shlomi, E Ruppin, R Sharan, et al. A direct comparison of protein interaction confidence assignment schemes. BMC Bioinformatics 7 (2006), p. 360.

[165] C L Myers and O G Troyanskaya. Context-sensitive data integration and prediction of biological networks. Bioinformatics 23 (2007), pp. 2322-2330.

[166] F Browne, H Wang, H Zheng, and F Azuaje. GRIP: A web-based system for constructing Gold Standard datasets for protein-protein interaction prediction. Source Code Biol Med 4 (2009), p. 2.

[167] R Jansen and M Gerstein. Analyzing protein function on a genomic scale: the importance of gold-standard positives and negatives for network prediction. Curr Opin Microbiol 7 (2004), pp. 535-545.

[168] I Lee, B Lehner, C Crombie, W Wong, et al. A single gene network accurately predicts phenotypic effects of gene perturbation in Caenorhabditis elegans. Nat Genet 40 (2008), pp. 181188.

[169] S Brohée, K Faust, G Lima-Mendez, O Sand, et al. NeAT: a toolbox for the analysis of biological networks, clusters, classes and pathways. Nucleic Acids Res 36 (Web Server issue) (2008), W444-451.

[170] C Brun, C Herrmann, and A Guénoche. Clustering proteins from interaction networks for the prediction of cellular functions. BMC Bioinformatics 5 (2004), p. 95.

[171] A J Enright, S Van Dongen, and C A Ouzounis. An efficient algorithm for large-scale detection of protein families. Nucleic Acids Res 30 (2002), pp. 1575-1584.

[172] Y Tao, L Sam, J Li, C Friedman, et al. Information theory applied to the sparse Gene Ontology annotation network to predict novel gene function. Bioinformatics 23 (2007), pp. 529-538.

[173] B A Shoemaker and A R Panchenko. Deciphering protein-protein interactions. Part II. Computational methods to predict protein and domain interaction partners. PLoS Comput Biol 3 (2007), e43.

[174] J Yu and F Fotouhi. Computational approaches for predicting protein-protein interactions: a survey. J Med Syst 30 (2006), pp. 39-44.

[175] Y Yamanishi, J P Vert, and M Kanehisa. Protein network inference from multiple genomic data: a supervised approach. Bioinformatics 20 Suppl 1 (2004), pp. 363-370.

[176] Y Qi, Z Bar-Joseph, and J Klein-Seetharaman. Evaluation of different biological data and computational classification methods for use in protein interaction prediction. Proteins 63 (2006), pp. 490-500.

[177] M S Scott and G J Barton. Probabilistic prediction and ranking of human protein-protein interactions. BMC Bioinformatics 8 (2007), p. 239. 
[178] B García-Jiménez, D Juan, I Ezkurdia, E Andrés-León, et al. Inference of functional relations in predicted protein networks with a machine learning approach. PLoS One 5 (2010), e9969.

[179] J R Bock and D A Gough. Whole-proteome interaction mining. Bioinformatics 19 (2003), pp. 125-134.

[180] A Ben-Hur and W S Noble. Kernel methods for predicting protein-protein interactions. Bioinformatics 21 Suppl 1 (2005), pp. 38-46.

[181] T-P Nguyen and T-B Ho. An integrative domain-based approach to predicting protein-protein interactions. J Bioinform Comput Biol 6 (2008), pp. 1115-1132.

[182] T P Mohamed, J G Carbonell, and M K Ganapathiraju. Active learning for human proteinprotein interaction prediction. BMC Bioinformatics 11 (2010), S57.

[183] T Aho, H Almusa, J Matilainen, A Larjo, et al. Reconstruction and validation of RefRec: a global model for the yeast molecular interaction network. PLoS One 5 (2010), e10662.

[184] S L Lo, C Z Cai, Y Z Chen, and M C Chung. Effect of training datasets on support vector machine prediction of protein-protein interactions. Proteomics 5 (2005), pp. 876-884.

[185] J Shen, J Zhang, X Luo, W Zhu, et al. Predicting protein-protein interactions based only on sequences information. Proc Natl Acad Sci U S A 104 (2007), pp. 4337-4341.

[186] B-Q Li, K-Y Feng, L Chen, T Huang, et al. Prediction of protein-protein interaction sites by random forest algorithm with mRMR and IFS. PloS One 7 (2012), e43927.

[187] E Rodgers-Melnick, M Culp, and S P DiFazio. Predicting whole genome protein interaction networks from primary sequence data in model and non-model organisms using ENTS. BMC Genomics 14 (2013), p. 608.

[188] R Pesch and R Zimmer. Complementing the eukaryotic protein interactome. PloS One 8 (2013), e66635.

[189] L J Lu, Y Xia, A Paccanaro, H Yu, et al. Assessing the limits of genomic data integration for predicting protein networks. Genome Res 15 (2005), pp. 945-953.

[190] Z Wang. Big data mining powers fungal research: recent advances in fission yeast systems biology approaches. Curr Genet 63 (2017), pp. 427-433.

[191] T V Vo, J Das, M J Meyer, N A Cordero, et al. A proteome-wide fission yeast interactome reveals network evolution principles from yeasts to human. Cell 164 (2016), pp. 310-323.

[192] C J Ryan, A Roguev, K Patrick, J Xu, et al. Hierarchical modularity and the evolution of genetic interactomes across species. Mol Cell 46 (2012), pp. 691-704.

[193] J Das, T V Vo, X Wei, J C Mellor, et al. Cross-species protein interactome mapping reveals species-specific wiring of stress response pathways. Sci Signal 6 (2013), ra38.

[194] A Roguev, S Bandyopadhyay, M Zofall, K Zhang, et al. Conservation and rewiring of functional modules revealed by an epistasis map in fission yeast. Science 322 (2008), pp. 405410.

[195] P Beltrao, J C Trinidad, D Fiedler, A Roguev, et al. Evolution of phosphoregulation: comparison of phosphorylation patterns across yeast species. PLoS Biol 7 (2009), e1000134.

[196] C J Ryan, N J Krogan, P Cunningham, and G Cagney. All or nothing: protein complexes flip essentiality between distantly related eukaryotes. Genome Biol Evol 5 (2013), pp. 1049-1059.

[197] E N Koch, M Costanzo, J Bellay, R Deshpande, et al. Conserved rules govern genetic interaction degree across species. Genome Biol (2012), R57. 
[198] C Ogris, D Guala, and E L L Sonnhammer. FunCoup 4: new species, data, and visualization. Nucleic Acids Res 46 (2018), pp. D601-D607.

[199] V Pancaldi, O S Saraç, C Rallis, J R McLean, et al. Predicting the fission yeast protein interaction network. G3 (Bethesda) 2 (2012), pp. 453-467.

[200] F Schoeters and P Van Dijck. Protein-protein interactions in Candida albicans. Front Microbiol 10 (2019), p. 1792.

[201] N A R Gow and B Yadav. Microbe Profile: Candida albicans: a shape-changing, opportunistic pathogenic fungus of humans. Microbiology (Reading) 163 (2017), pp. 1145-1147.

[202] B Stynen, P Van Dijck, and H Tournu. A CUG codon adapted two-hybrid system for the pathogenic fungus Candida albicans. Nucleic Acids Res 38 (2010), e184.

[203] F Schoeters, C A Munro, C d'Enfert, and P Van Dijck. A high-throughput Candida albicans two-hybrid system. mSphere 3 (2018), e00391-18.

[204] T R O’Meara, M J O’Meara, E J Polvi, M R Pourhaghighi, et al. Global proteomic analyses define an environmentally contingent Hsp90 interactome and reveal chaperone-dependent regulation of stress granule proteins and the R2TP complex in a fungal pathogen. PLoS Biol 17 (2019), e3000358.

[205] I N Kaneva, I M Sudbery, M J Dickman, and P E Sudbery. Proteins that physically interact with the phosphatase Cdc14 in Candida albicans have diverse roles in the cell cycle. Sci Rep 9 (2019), p. 6258.

[206] M Urban, A Lysenko, E I Janowska-Sedja, C Rawlings, et al. PHI-Nets: A network resource for Ascomycete fungal pathogens to annotate and identify putative virulence interacting proteins and siRNAs. Frontiers Microbiol 10 (2019), p. 2721.

[207] J-P Latgé. Aspergillus fumigatus and aspergillosis. Clin Microbiol Rev 12 (1999), pp. 310350.

[208] D W Parry, P Jenkinson, and L McLeod. Fusarium ear blight (scab) in small grain cereals - a review. Plant Pathol 44 (1995), pp. 207-238.

[209] X Liu, W-H Tang, X-M Zhao, and L Chen. A network approach to predict pathogenic genes for Fusarium graminearum. PloS One 5 (2010), e13021.

[210] Z-Y Kuo, Y-J Chuang, C-C Chao, F-C Liu, et al. Identification of infection- and defenserelated genes via a dynamic host-pathogen interaction network using a Candida albicanszebrafish infection model. J Innate Immun 5 (2013), pp. 137-152.

[211] Y-C Wang, C Lin, M-T Chuang, W-P Hsieh, et al. Interspecies protein-protein interaction network construction for characterization of host-pathogen interactions: a Candida albicanszebrafish interaction study. BMC Syst Biol 7 (2013), p. 79.

[212] Y-C Wang, I-C Tsai, C Lin, W-P Hsieh, et al. Essential functional modules for pathogenic and defensive mechanisms in Candida albicans infections. Biomed Res Int 2014 (2014), p. 136130.

[213] C W Remmele, C H Luther, J Balkenhol, T Dandekar, et al. Integrated inference and evaluation of host-fungi interaction networks. Front Microbiol 6 (2015), p. 764.

[214] S Ma, Q Song, H Tao, A Harrison, et al. Prediction of protein-protein interactions between fungus (Magnaporthe grisea) and rice (Oryza sativa L.). Briefings Bioinform 20 (2019), pp. $448-456$. 
[215] S Yang, H Li, H He, Y Zhou, et al. Critical assessment and performance improvement of plant-pathogen protein-protein interaction prediction methods. Brief Bioinform 20 (2019), pp. 274-287.

[216] X Xu, T Liu, J Yang, L Chen, et al. The first succinylome profile of Trichophyton rubrum reveals lysine succinylation on proteins involved in various key cellular processes. $B M C \mathrm{Ge}$ nomics 18 (2017), p. 577.

[217] S Li, B Musungu, D Lightfoot, and P Ji. The interactomic analysis reveals pathogenic protein networks in Phomopsis longicolla underlying seed decay of soybean. Front Genet 9 (2018), p. 104.

[218] T-Y Wang, F He, Q-W Hu, and Z Zhang. A predicted protein-protein interaction network of the filamentous fungus Neurospora crassa. Mol Biosyst 7 (2011), pp. 2278-2285.

[219] C Chang, J L Bowman, and E M Meyerowitz. Field guide to plant model systems. Cell 167 (2016), pp. 325-339.

[220] J Van Leene, J Hollunder, D Eeckhout, G Persiau, et al. Targeted interactomics reveals a complex core cell cycle machinery in Arabidopsis thaliana. Mol Syst Biol 6 (2010), p. 397.

[221] K Klopffleisch, N Phan, K Augustin, R S Bayne, et al. Arabidopsis G-protein interactome reveals connections to cell wall carbohydrates and morphogenesis. Mol Syst Biol 7 (2011), p. 532 .

[222] Arabidopsis Interactome Mapping Consortium. Evidence for network evolution in an Arabidopsis interactome map. Science 333 (2011), pp. 601-607.

[223] S A Trigg, R M Garza, A MacWilliams, J R Nery, et al. CrY2H-seq: a massively multiplexed assay for deep-coverage interactome mapping. Nat Methods 14 (2017), pp. 819-825.

[224] M Altmann, S Altmann, P A Rodriguez, B Weller, et al. Extensive signal integration by the phytohormone protein network. Nature 583 (2020), pp. 271-276.

[225] S C Popescu, G V Popescu, S Bachan, Z Zhang, et al. Differential binding of calmodulinrelated proteins to their targets revealed through high-density Arabidopsis protein microarrays. Proc Natl Acad Sci US A 104 (2007), pp. 4730-4735.

[226] S C Popescu, G V Popescu, S Bachan, Z Zhang, et al. MAPK target networks in Arabidopsis thaliana revealed using functional protein microarrays. Genes Dev 23 (2009), pp. 80-92.

[227] A M Jones, Y Xuan, M Xu, R-S Wang, et al. Border control-a membrane-linked interactome of Arabidopsis. Science 344 (2014), pp. 711-716.

[228] F Zhang, S Liu, L Li, K Zuo, et al. Genome-wide inference of protein-protein interaction networks identifies crosstalk in abscisic acid signaling. Plant Physiol 171 (2016), pp. 15111522.

[229] J Zhao, Y Lei, J Hong, C Zheng, et al. AraPPINet: an updated interactome for the analysis of hormone signaling crosstalk in Arabidopsis thaliana. Front Plant Sci 10 (2019), p. 870.

[230] Q-B Yu, G Li, G Wang, J-C Sun, et al. Construction of a chloroplast protein interaction network and functional mining of photosynthetic proteins in Arabidopsis thaliana. Cell Res 18 (2008), pp. 1007-1019.

[231] Z Ding and D Kihara. Computational identification of protein-protein interactions in model plant proteomes. Sci Rep 9 (2019), p. 8740.

[232] M Lin, X Shen, and X Chen. PAIR: the predicted Arabidopsis interactome resource. Nucleic Acids Res 39 (2011), pp. D1134-D1140. 
[233] H Li, S Yang, C Wang, Y Zhou, et al. AraPPISite: a database of fine-grained protein-protein interaction site annotations for Arabidopsis thaliana. Plant Mol Biol 92 (2016), pp. 105-116.

[234] J Van Leene, J Boruc, G De Jaeger, E Russinova, et al. A kaleidoscopic view of the Arabidopsis core cell cycle interactome. Trends Plant Sci 16 (2011), pp. 141-150.

[235] Q Lv, Y Lan, Y Shi, H Wang, et al. AtPID: a genome-scale resource for genotype-phenotype associations in Arabidopsis. Nucleic Acids Res 45 (2017), pp. D1060-D1063.

[236] S De Bodt, S Proost, K Vandepoele, P Rouzé, et al. Predicting protein-protein interactions in Arabidopsis thaliana through integration of orthology, gene ontology and co-expression. BMC Genomics 10 (2009), p. 288.

[237] I Lee, B Ambaru, P Thakkar, E M Marcotte, et al. Rational association of genes with traits using a genome-scale gene network for Arabidopsis thaliana. Nat Biotechnol 28 (2010), pp. 149156.

[238] X Yang, S Yang, H Qi, T Wang, et al. PlaPPISite: a comprehensive resource for plant proteinprotein interaction sites. BMC Plant Biol 20 (2020), p. 61.

[239] X-G Zhu, J P Lynch, D S LeBauer, A J Millar, et al. Plants in silico: why, why now and what?-an integrative platform for plant systems biology research. Plant Cell Environ 39 (2016), pp. 1049-1057.

[240] S Struk, A Jacobs, E Sánchez Martín-Fontecha, K Gevaert, et al. Exploring the proteinprotein interaction landscape in plants. Plant Cell Environ 42 (2019), pp. 387-409.

[241] J F Uhrig. Protein interaction networks in plants. Planta 224 (2006), pp. 771-781.

[242] P Braun, S Aubourg, J Van Leene, G De Jaeger, et al. Plant protein interactomes. Annu Rev Plant Biol 64 (2013), pp. 161-187.

[243] D Di Silvestre, A Bergamaschi, E Bellini, and P Mauri. Large scale proteomic data and network-based systems biology approaches to explore the plant world. Proteomes 6 (2018), p. 27.

[244] S S Sahu, T Weirick, and R Kaundal. Predicting genome-scale Arabidopsis-Pseudomonas syringae interactome using domain and interolog-based approaches. BMC Bioinformatics 15 Suppl 11 (2014), S13.

[245] A K Biswal, E W McConnell, E G Werth, S-F Lo, et al. The nucleotide-dependent interactome of rice heterotrimeric G-protein $\alpha$-subunit. Proteomics 19 (2019), e1800385.

[246] X Ding, T Richter, M Chen, H Fujii, et al. A rice kinase-protein interaction map. Plant Physiol 149 (2009), pp. 1478-1492.

[247] Y-S Seo, M Chern, L E Bartley, M Han, et al. Towards establishment of a rice stress response interactome. PLoS Genet 7 (2011), e1002020.

[248] C-L Ho, Y Wu, H-B Shen, N J Provart, et al. A predicted protein interactome for rice. Rice (N Y) 5 (2012), p. 15.

[249] S Liu, Y Liu, J Zhao, S Cai, et al. A computational interactome for prioritizing genes associated with complex agronomic traits in rice (Oryza sativa). Plant J 90 (2017), pp. 177188.

[250] H Gu, P Zhu, Y Jiao, Y Meng, et al. PRIN: a predicted rice interactome network. BMC Bioinformatics 12 (2011), p. 161. 
[251] P Zhu, H Gu, Y Jiao, D Huang, et al. Computational identification of protein-protein interactions in rice based on the predicted rice interactome network. Genomics Proteomics Bioinformatics (2011), pp. 128-137.

[252] I Lee, Y-S Seo, D Coltrane, S Hwang, et al. Genetic dissection of the biotic stress response using a genome-scale gene network for rice. Proc Natl Acad Sci U S A 108 (2011), pp. 1854818553.

[253] T Lee, T Oh, S Yang, J Shin, et al. RiceNet v2: an improved network prioritization server for rice genes. Nucleic Acids Res 43 (2015), W122-W127.

[254] S Lee, T Lee, S Yang, and I Lee. BarleyNet: A network-based functional omics analysis server for cultivated barley, Hordeum vulgare L. Front Plant Sci 11 (2020), p. 98.

[255] B Musungu, D Bhatnagar, R L Brown, A M Fakhoury, et al. A predicted protein interactome identifies conserved global networks and disease resistance subnetworks in maize. Front Genet 6 (2015), p. 201.

[256] J Bhardwaj, I Gangwar, G Panzade, R Shankar, et al. Global de novo protein-protein interactome elucidates interactions of drought-responsive proteins in horse gram (Macrotyloma uniflorum). J Proteome Res 15 (2016), pp. 1794-1809.

[257] J Yue, W Xu, R Ban, S Huang, et al. PTIR: predicted tomato interactome resource. Sci Rep 6 (2016), p. 25047.

[258] J Yang, K Osman, M Iqbal, D J Stekel, et al. Inferring the Brassica rapa interactome using protein-protein interaction data from Arabidopsis thaliana. Front Plant Sci 3 (2012), p. 297.

[259] E Fitzek and M Geisler. A predicted interactome for coffee (Coffea canephora var robusta). J Plant Mol Biol Biotechnol 2 (2011), pp. 34-46.

[260] V Singh Gand Singh and V Singh. Construction and analysis of an interologous proteinprotein interaction network of Camellia sinensis leaf (TeaLIPIN) from RNA-Seq data sets. Plant Cell Rep 38 (2019), pp. 1249-1262.

[261] R Thanasomboon, S Kalapanulak, S Netrphan, and T Saithong. Prediction of cassava protein interactome based on interolog method. Sci Rep 7 (2017), p. 17206.

[262] R Thanasomboon, S Kalapanulak, S Netrphan, and T Saithong. Exploring dynamic proteinprotein interactions in cassava through the integrative interactome network. Sci Rep 10 (2020), p. 6510 .

[263] Y-D Ding, J-W Chang, J Guo, D Chen, et al. Prediction and functional analysis of the sweet orange protein-protein interaction network. BMC Plant Biol 14 (2014), p. 213.

[264] V Singh, G Singh, and V Singh. TulsiPIN: an interologous protein interactome of Ocimum tenuiflorum. J Proteome Res 19 (2020), pp. 884-899.

[265] K Vandereyken, B Van Leene Jand De Coninck, and B P A Cammue. Hub protein controversy: taking a closer look at plant stress response hubs. Front Plant Sci 9 (2018), p. 694.

[266] L Zhang, J-Y Liu, H Gu, Y Du, et al. Bradyrhizobium diazoefficiens USDA 110-Glycine max interactome provides candidate proteins associated with symbiosis. J Proteome Res 17 (2018), pp. 3061-3074.

[267] R González-Fernández, E Prats, and J V Jorrín-Novo. Proteomics of plant pathogenic fungi. J Biomed Biotechnol 2010 (2010), p. 932527. 
[268] A Chaiboonchoe, L Ghamsari, B Dohai, P Ng, et al. Systems level analysis of the Chlamydomonas reinhardtii metabolic network reveals variability in evolutionary co-conservation. Mol Biosyst 12 (2016), pp. 2394-2407.

[269] Y Wang, S Lin, Q Song, K Li, et al. Genome-wide identification of heat shock proteins (Hsps) and Hsp interactors in rice: Hsp70s as a case study. BMC Genomics 15 (2014), p. 344.

[270] A Sapkota, X Liu, X-M Zhao, Y Cao, et al. DIPOS: database of interacting proteins in Oryza sativa. Mol Biosyst 7 (2011), pp. 2615-2621.

[271] S Schuette, B Piatkowski, A Corley, D Lang, et al. Predicted protein-protein interactions in the moss Physcomitrella patens: a new bioinformatic resource. BMC Bioinformatics 16 (2015), p. 89.

[272] C Ji, X Cao, C Yao, S Xue, et al. Protein-protein interaction network of the marine microalga Tetraselmis subcordiformis: prediction and application for starch metabolism analysis. 41 (2014), pp. 1287-1296.

[273] G Zhu, A Wu, X-J Xu, P-P Xiao, et al. PPIM: A protein-protein interaction database for maize. Plant Physiol 170 (2016), pp. 618-626.

[274] T Lee, S Lee, S Yang, and I Lee. MaizeNet: a co-functional network for network-assisted systems genetics in Zea mays. Plant Jy 99 (2019), pp. 571-582.

[275] V M Howick, A J C Russell, T Andrews, H Heaton, et al. The Malaria Cell Atlas: Single parasite transcriptomes across the complete Plasmodium life cycle. Science 365 (2019), eaaw2619.

[276] D J LaCount. Interactome mapping in malaria parasites: challenges and opportunities. Methods Mol Biol 812 (2012), pp. 121-145.

[277] D J LaCount, M Vignali, R Chettier, A Phansalkar, et al. A protein interaction network of the malaria parasite Plasmodium falciparum. Nature 438 (2005), pp. 103-107.

[278] T Hase, Y Niimura, and H Tanaka. Difference in gene duplicability may explain the difference in overall structure of protein-protein interaction networks among eukaryotes. BMC Evol Biol 10 (2010), p. 358.

[279] S Suthram, T Sittler, and T Ideker. The Plasmodium protein network diverges from those of other eukaryotes. Nature 438 (2005), pp. 108-112.

[280] M D Dyer, T M Murali, and B W. Sobral. Computational prediction of host-pathogen proteinprotein interactions. Bioinformatics 23 (2007), pp. i159-i166.

[281] S Wuchty. Computational prediction of host-parasite protein interactions between P. falciparum and H. sapiens. PloS One 6 (2011), e26960.

[282] A Rao, M K Kumar, T Joseph, and G Bulusu. Cerebral malaria: insights from host-parasite protein-protein interactions. Malar $J 9$ (2010), p. 155.

[283] A Suratanee and K Plaimas. Heterogeneous network model to identify potential associations between Plasmodium vivax and human proteins. Int J Mol Sci 21 (2020), p. 1310.

[284] H W Murray, J D Berman, C R Davies, and N G Saravia. Advances in leishmaniasis. Lancet 366 (2005), pp. 1561-1577.

[285] J A Pérez-Molina and I Molina. Chagas disease. Lancet 391 (2018), pp. 82-94.

[286] A Ponte-Sucre. An overview of Trypanosoma brucei infections: an intense host-parasite interaction. Front Microbiol 7 (2016), p. 2126. 
[287] C R Dos Santos Vasconcelos, T de Lima Campos, and A M Rezende. Building proteinprotein interaction networks for Leishmania species through protein structural information. BMC Bioinformatics 19 (2018), p. 85.

[288] A M Rezende, E L Folador, D de M Resende, and J C Ruiz. Computational prediction of protein-protein interactions in Leishmania predicted proteomes. PloS One 7 (2012), e51304.

[289] R Watanabe Costa, M F Batista, I Meneghelli, R O Vidal, et al. Comparative analysis of the secretome and interactome of Trypanosoma cruzi and Trypanosoma rangeli reveals species specific immune response modulating proteins. Front Immunol 11 (2020), p. 1774.

[290] H M Kariithi, S Boeren, E K Murungi, J M Vlak, et al. A proteomics approach reveals molecular manipulators of distinct cellular processes in the salivary glands of Glossina $\mathrm{m}$. morsitans in response to Trypanosoma b. brucei infections. Parasit Vectors 9 (2016), p. 424.

[291] E Muriithi, J Kinyua, and S G Nyanjom. In silico prediction of protein-protein interaction between Glossina m. morsitans (Westwood, 1851) and Trypanosoma brucei (Kinetoplastida: Trypanosomatidae). Bioscience Horizons 11 (2018), hzy005.

[292] V H Gazestani, C W Yip, N Nikpour, N Berghuis, et al. TrypsNetDB: An integrated framework for the functional characterization of trypanosomatid proteins. PLoS Negl Trop Dis 11 (2017), e0005368.

[293] S V Date and C J Stoeckert. Computational modeling of the Plasmodium falciparum interactome reveals protein function on a genome-wide scale. Genome Res 16 (2006), pp. 542549.

[294] Y Cuesta-Astroz, A Santos, G Oliveira, and L J Jensen. Analysis of predicted host-parasite interactomes reveals commonalities and specificities related to parasitic lifestyle and tissues tropism. Front Immunol 10 (2019), p. 212.

[295] A F Flórez, D Park, J Bhak, B-C Kim, et al. Protein network prediction and topological analysis in Leishmania major as a tool for drug target selection. BMC Bioinformatics 11 (2010), p. 484.

[296] S R Pavithra, R Kumar, and U Tatu. Systems analysis of chaperone networks in the malarial parasite Plasmodium falciparum. PLoS Comput Biol 3 (2007), pp. 1701-1715.

[297] A Mitrofanova, S Kleinberg, J Carlton, S Kasif, et al. Predicting malaria interactome classifications from time-course transcriptomic data along the intraerythrocytic developmental cycle. Artif Intell Med 49 (2010), pp. 167-176.

[298] C Hillier, M Pardo, L Yu, E Bushell, et al. Landscape of the Plasmodium interactome reveals both conserved and species-specific functionality. Cell Rep 28 (2019), 1635-1647.e5.

[299] H Huang, E E Winter, H Wang, K G Weinstock, et al. Evolutionary conservation and selection of human disease gene orthologs in the rat and mouse genomes. Genome Biol 5 (2004), R47.

[300] T Ravasi, H Suzuki, C V Cannistraci, S Katayama, et al. An atlas of combinatorial transcriptional regulation in mouse and man. Cell 140 (2010), pp. 744-752.

[301] Q Cao, X Wang, M Zhao, R Yang, et al. The central role of EED in the orchestration of polycomb group complexes. Nature Commun 5 (2014), p. 3127.

[302] J Li, W Zhang, H Yang, D P Howrigan, et al. Spatiotemporal profile of postsynaptic interactomes integrates components of complex brain disorders. Nat Neurosci 20 (2017), pp. 11501161. 
[303] T Zhang, W Du, A F Wilson, S H Namekawa, et al. Fancd2 in vivo interaction network reveals a non-canonical role in mitochondrial function. Sci Rep 7 (2017), p. 45626.

[304] S Zhang, N A Williamson, and M A Bogoyevitch. Complementary proteomics strategies capture an ataxin-1 interactome in Neuro-2a cells. Sci Data 5 (2018), p. 180262.

[305] F Arbogast, J Arnold, P Hammann, L Kuhn, et al. ATG5 is required for B cell polarization and presentation of particulate antigens. Autophagy 15 (2 2019), pp. 280-294.

[306] R Pourhaghighi, P E A Ash, S Phanse, F Goebels, et al. BraInMap elucidates the macromolecular connectivity landscape of mammalian brain. Cell Syst 10 (2020), 333-350.e14.

[307] C Wan, B Borgeson, S Phanse, F Tu, et al. Panorama of ancient metazoan macromolecular complexes. Nature 525 (2015), pp. 339-344.

[308] M A Skinnider, N E Scott, A Prudova, C H Kerr, et al. An atlas of protein-protein interactions across mouse tissues. Cell 184 (2021), 4073-4089.e17.

[309] S Yellaboina, D B. Dudekula, and M S Ko. Prediction of evolutionarily conserved interologs in Mus musculus. BMC Genomics 9 (2008), p. 465.

[310] C J Shin, M J Davis, and M A Ragan. Towards the mammalian interactome: Inference of a core mammalian interaction set in mouse. Proteomics 9 (2009), pp. 5256-5266.

[311] X Li, H Cai, J Xu, S Ying, et al. A mouse protein interactome through combined literature mining with multiple sources of interaction evidence. Amino Acids 38 (2010), pp. 1237-1252.

[312] G Alanis-Lobato, J S. Möllmann, M H Schaefer, and M A Andrade-Navarro. MIPPIE: the mouse integrated protein-protein interaction reference. Database (Oxford) 2020 (2020), baaa035.

[313] W K Kim, C Krumpelman, and E M Marcotte. Inferring mouse gene functions from genomicscale data using a combined functional network/classification strategy. Genome Biology 9 Suppl 1 (2008), S5.

[314] N Guillemin, M Bonnet, C Jurie, and B Picard. Functional analysis of beef tenderness. J Proteomics 75 (2011), pp. 352-365.

[315] E Kamau, S G Nyanjom, M Wamalwa, and J Ng'ang'a. Prediction of protein-protein interactions between Theileria parva and Bos taurus based on sequence homology. Bioscience Horizons 9 (2016), hzw006.

[316] F Wang, B Song, X Zhao, Y Miao, et al. Prediction and analysis of the protein-protein interaction networks for chickens, cattle, dogs, horses and rabbits. Curr Bioinform 11 (2016), pp. 131-142.

[317] C von Mering, M Huynen, D Jaeggi, S Schmidt, et al. STRING: a database of predicted functional associations between proteins. Nucleic Acids Res 31 (2003), pp. 258-261.

[318] E Kim, D Bae, S Yang, G Ko, et al. BiomeNet: a database for construction and analysis of functional interaction networks for any species with a sequenced genome. Bioinformatics 36 (2020), pp. 1584-1589.

[319] Y Chen, Y Liu, M Du, W Zhang, et al. Constructing a comprehensive gene co-expression based interactome in Bos taurus. PeerJ 5 (2017), e4107.

[320] Y-T Tao, X-B Ding, J Jin, H-B Zhang, et al. Predicted rat interactome database and gene set linkage analysis. Database (Oxford) 2020 (2020), baaa086.

[321] F Wang, M Liu, B Song, D Li, et al. Prediction and characterization of protein-protein interaction networks in swine. Proteome Sci 10 (2012), p. 2. 
[322] F Dreher, A Kamburov, and R Herwig. Construction of a pig physical interactome using sequence homology and a comprehensive reference human interactome. Evol Bioinform Online 8 (2012), pp. 119-126.

[323] J Sprague, L Bayraktaroglu, D Clements, T Conlin, et al. The Zebrafish Information Network: the zebrafish model organism database. Nucleic Acids Res 34 (2006), pp. D581-D585.

[324] L-C Tseng, C Zhang, C-M Cheng, H Xu, et al. New classes of mind bomb-interacting proteins identified from yeast two-hybrid screens. PLoS One 9 (2014), e93394.

[325] A Alexeyenko, D M Wassenberg, E K Lobenhofer, J Yen, et al. Dynamic zebrafish interactome reveals transcriptional mechanisms of dioxin toxicity. PloS One 5 (2010), e10465.

[326] K Waiho, N Afiqah-Aleng, M T M Iryani, and H Fazhan. Protein-protein interaction network: an emerging tool for understanding fish disease in aquaculture. Rev Aquac 13 (), pp. 156-177.

[327] H Guo, J Zhang, Y Wang, C Bu, et al. Comparative proteomic analysis of lysine acetylation in fish CIK cells infected with aquareovirus. Int J Mol Sci 18 (2017), p. 2419.

[328] H Li, X Huang, Z Zeng, X-X Peng, et al. Identification of the interactome between fish plasma proteins and Edwardsiella tarda reveals tissue-specific strategies against bacterial infection. Int J Biochem Cell Biol 78 (2016), pp. 260-267.

[329] Y Liu, H Zhang, Y Liu, H Li, et al. Determination of the heterogeneous interactome between Edwardsiella tarda and fish gills. J Proteomics 75 (2012), pp. 1119-1128.

[330] H Li, Q-F Zhu, X-X Peng, and B Peng. Interactome of E. piscicida and grouper liver proteins reveals strategies of bacterial infection and host immune response. Sci Rep 7 (2017), p. 39824.

[331] G Kumar, K Hummel, K Noebauer, T J Welch, et al. Proteome analysis reveals a role of rainbow trout lymphoid organs during Yersinia ruckeri infection process. Sci Rep 8 (2018), p. 13998.

[332] Z Li, X Liu, J Liu, K Zhang, et al. Transcriptome profiling based on protein-protein interaction networks provides a core set of genes for understanding blood immune response mechanisms against Edwardsiella tarda infection in Japanese flounder (Paralichthys olivaceus). Dev Comp Immunol 78 (2018), pp. 100-113.

[333] M Carrera, B Cañas, and J M Gallardo. The sarcoplasmic fish proteome: pathways, metabolic networks and potential bioactive peptides for nutritional inferences. J Proteomics 78 (2013), pp. 211-220.

[334] A F Millan-Cubillo, M Martin-Perez, A Ibarz, J Fernandez-Borras, et al. Proteomic characterization of primary cultured myocytes in a fish model at different myogenesis stages. Sci Rep 9 (2019), p. 14126.

[335] C Raposo de Magalhães, D Schrama, A P Farinha, D Revets, et al. Protein changes as robust signatures of fish chronic stress: a proteomics approach to fish welfare research. $B M C$ Genomics 21 (2020), p. 309.

[336] Z Xu, L Gan, T Li, C Xu, et al. Transcriptome profiling and molecular pathway analysis of genes in association with salinity adaptation in Nile tilapia Oreochromis niloticus. PloS One 10 (2015), e0136506.

[337] K A Matthews, T C Kaufman, and W M Gelbart. Research resources for Drosophila: the expanding universe. Nat Rev Genet 6 (2005), pp. 179-193.

[338] L Giot, J S Bader, C Brouwer, A Chaudhuri, et al. A protein interaction map of Drosophila melanogaster. Science 302 (2003), pp. 1727-1736. 
[339] C A Stanyon, G Liu, B A Mangiola, N Patel, et al. A Drosophila protein-interaction map centered on cell-cycle regulators. Genome Biol 5 (2004), R96.

[340] E Formstecher, S Aresta, V Collura, A Hamburger, et al. Protein interaction mapping: a Drosophila case study. Genome Res 15 (2005), pp. 376-384.

[341] L Shokri, S Inukai, A Hafner, K Weinand, et al. A comprehensive Drosophila melanogaster transcription factor interactome. Cell Rep 27 (2019), 955-970.e7.

[342] J S Rees, N Lowe, I M Armean, J Roote, et al. In vivo analysis of proteomes and interactomes using Parallel Affinity Capture (iPAC) coupled to mass spectrometry. Mol Cell Proteomics 10 (2011), p. M110.002386.

[343] K G Guruharsha, J-F Rual, B Zhai, J Mintseris, et al. A protein complex network of Drosophila melanogaster. Cell 147 (2011), pp. 690-703.

[344] A A Friedman, G Tucker, R Singh, D Yan, et al. Proteomic and functional genomic landscape of receptor tyrosine kinase and Ras to extracellular signal-regulated kinase signaling. Sci Signal 4 (2011), rs10.

[345] H Fukuyama, Y Verdier, Y Guan, C Makino-Okamura, et al. Landscape of protein-protein interactions in Drosophila immune deficiency signaling during bacterial challenge. Proc Natl Acad Sci U S A 110 (2013), pp. 10717-10722.

[346] Y Kwon, A Vinayagam, X Sun, N Dephoure, et al. The Hippo signaling pathway interactome. Science 342 (2013), pp. 737-740.

[347] D Y Rhee, D-Y Cho, B Zhai, M Slattery, et al. Transcription factor networks in Drosophila melanogaster. Cell Rep 8 (2014), pp. 2031-2043.

[348] A K Gillingham, R Sinka, I L Torres, K S Lilley, et al. Toward a comprehensive map of the effectors of Rab GTPases. Dev Cell 31 (2014), pp. 358-373.

[349] A Vinayagam, M M Kulkarni, R Sopko, X Sun, et al. An integrative analysis of the InR/PI3K/Akt network identifies the dynamic response to insulin signaling. Cell Rep 16 (2016), pp. 30623074 .

[350] R Stegeman, P J Spreacker, S K Swanson, R Stephenson, et al. The spliceosomal protein SF3B5 is a novel component of Drosophila SAGA that functions in gene expression independent of splicing. J Mol Biol 428 (2016), pp. 3632-3649.

[351] A Lunardi, G Di Minin, P Provero, M Dal Ferro, et al. A genome-scale protein interaction profile of Drosophila p53 uncovers additional nodes of the human p53 network. Proc Natl Acad Sci US A 107 (2010), pp. 6322-6327.

[352] E Özkan, R A Carrillo, C L Eastman, R Weiszmann, et al. An extracellular interactome of immunoglobulin and LRR proteins reveals receptor-ligand networks. Cell 154 (2013), pp. 228239.

[353] A W Reinke, J Baek, O Ashenberg, and A E Keating. Networks of bZIP protein-protein interactions diversified over a billion years of evolution. Science 340 (2013), pp. 730-734.

[354] X-B Ding, J Jin, Y-T Tao, W-P Guo, et al. Predicted Drosophila Interactome Resource and web tool for functional interpretation of differentially expressed genes. Database (Oxford) 2020 (2020), baaa005.

[355] J Yu, S Pacifico, G Liu, and R L Finley. DroID: the Drosophila Interactions Database, a comprehensive resource for annotated gene and protein interactions. BMC Genomics 9 (2008), p. 461. 
[356] T Murali, S Pacifico, J Yu, S Guest, et al. DroID 2011: a comprehensive, integrated resource for protein, transcription factor, RNA and gene interactions for Drosophila. Nucleic Acids Res 39 (2011), pp. D736-D743.

[357] X Guo, Y Xu, G Bian, A D Pike, et al. Response of the mosquito protein interaction network to dengue infection. BMC Genomics 11 (2010), p. 380.

[358] D Mairiang, H Zhang, A Sodja, T Murali, et al. Identification of new protein interactions between dengue fever virus and its hosts, human and mosquito. PloS One 8 (2013), e53535.

[359] J M Doolittle and S M Gomez. Mapping protein interactions between Dengue virus and its human and insect hosts. PLoS Negl Trop Dis 5 (2011), e954.

[360] S K Gupta, M Srivastava, Ö Osmanoglu, and T Dandekar. Genome-wide inference of the Camponotus floridanus protein-protein interaction network using homologous mapping and interacting domain profile pairs. Sci Rep 10 (2020), p. 2334.

[361] R Sumathy, A S K Rao, N Chandrakanth, and V K Gopalakrishnan. In silico identification of protein-protein interactions in Silkworm, Bombyx mori. Bioinformation 10 (2014), pp. 56-62.

[362] L ZM Hu, F Goebels, J H Tan, E Wolf, et al. EPIC: software toolkit for elution profile-based inference of protein complexes. Nat Methods 16 (2019), pp. 737-742.

[363] S J Boulton. Combined functional genomic maps of the C. elegans DNA damage response. Science 295 (2002), pp. 127-131.

[364] L Xu, Y Wei, J Reboul, P Vaglio, et al. BTB proteins are substrate-specific adaptors in an SCF-like modular ubiquitin ligase containing CUL-3. Nature 425 (2003), pp. 316-321.

[365] X Xin, J-F Rual, T Hirozane-Kishikawa, D E Hill, et al. Shifted transversal design smartpooling for high coverage interactome mapping. Genome Res 19 (2009), pp. 1262-1269.

[366] N Lenfant, J Polanowska, S Bamps, S Omi, et al. A genome-wide study of PDZ-domain interactions in $C$. elegans reveals a high frequency of non-canonical binding. BMC Genomics 11 (2010), p. 671.

[367] T Koorman, D Klompstra, M van der Voet, I Lemmens, et al. A combined binary interaction and phenotypic map of C. elegans cell polarity proteins. Nat Cell Biol 18 (2016), pp. 337-346.

[368] M Boxem, Z Maliga, N Klitgord, N Li, et al. A protein domain-based interactome network for C. elegans early embryogenesis. Cell 134 (2008), pp. 534-545.

[369] A B Byrne, M T Weirauch, V Wong, M Koeva, et al. A global analysis of genetic interactions in Caenorhabditis elegans. J Biol 6 (2007), p. 8.

[370] S M O'Rourke, M D Dorfman, J C Carter, and B Bowerman. Dynein modifiers in C. elegans: light chains suppress conditional heavy chain mutants. PLoS Genet 3 (2007), e128.

[371] Liquan Cai, Dan Wang, Alfred L. Fisher, and Zhou Wang. Identification of a genetic interaction between the tumor suppressor EAF2 and the retinoblastoma protein $(\mathrm{Rb})$ signaling pathway in C. elegans and prostate cancer cells. Biochem Biophys Res Commun 447 (2014), pp. 292-298.

[372] J Ceron, J-F Rual, A Chandra, D Dupuy, et al. Large-scale RNAi screens identify novel genes that interact with the $C$. elegans retinoblastoma pathway as well as splicing-related components with synMuv B activity. BMC Dev Biol 7 (2007), p. 30.

[373] B Lehner, C Crombie, J Tischler, A Fortunato, et al. Systematic mapping of genetic interactions in Caenorhabditis elegans identifies common modifiers of diverse signaling pathways. Nat Genet 38 (2006), pp. 896-903. 
[374] C. elegans Sequencing Consortium. Genome sequence of the nematode C. elegans: a platform for investigating biology. Science 282 (1998), pp. 2012-2018.

[375] S Remmelzwaal and M Boxem. Protein interactome mapping in Caenorhabditis elegans. Curr Opin Syst Biol 13 (2019), pp. 1-9.

[376] S Li, C M Armstrong, N Bertin, $\mathrm{H} \mathrm{Ge}$, et al. A map of the interactome network of the metazoan C. elegans. Science 303 (2004), pp. 540-543.

[377] N Simonis, J-F Rual, A-R Carvunis, M Tasan, et al. Empirically controlled mapping of the Caenorhabditis elegans protein-protein interactome network. Nat Methods 6 (2009), pp. 4754.

[378] J S Reece-Hoyes, C Pons, A Diallo, A Mori, et al. Extensive rewiring and complex evolutionary dynamics in a C. elegans multiparameter transcription factor network. Molecular cell 51 (2013), pp. 116-127.

[379] K C Gunsalus, H Ge, A J Schetter, D S Goldberg, et al. Predictive models of molecular machines involved in Caenorhabditis elegans early embryogenesis. Nature 436 (2005), pp. 861865.

[380] P-C Chen, L Ruan, J Jin, Y-T Tao, et al. Predicted functional interactome of Caenorhabditis elegans and a web tool for the functional interpretation of differentially expressed genes. Biol Direct 15 (2020), pp. 1-11.

[381] X-T Huang, Y Zhu, L L Hang Chan, Z Zhao, et al. An integrative C. elegans protein-protein interaction network with reliability assessment based on a probabilistic graphical model. Mol Biosyst 12 (2016), pp. 85-92.

[382] K C Gunsalus. A Caenorhabditis elegans genetic-interaction map wiggles into view. J Biol 7 (3 2008), p. 8.

[383] K C Gunsalus and K Rhrissorrakrai. Networks in Caenorhabditis elegans. Curr Opin Genet Dev 21 (2011), pp. 787-798.

[384] C M Taylor, K Fischer, S Abubucker, Z Wang, et al. Targeting protein-protein interactions for parasite control. PloS One 6 (2011), e18381.

[385] M Berriman, B J Haas, P T LoVerde, R A Wilson, et al. The genome of the blood fluke Schistosoma mansoni. Nature 460 (2009), pp. 352-358.

[386] F Luo, M Yin, X Mo, C Sun, et al. An improved genome assembly of the fluke Schistosoma japonicum. PLoS Negl Trop Dis 13 (2019), e0007612.

[387] J White Bear, T Long, D Skinner, and J H McKerrow. Predictions of novel Schistosoma mansoni - human protein interactions consistent with experimental data. Sci Rep 8 (2018), p. 13092.

[388] S Caby, L Pagliazzo, J Lancelot, J-M Saliou, et al. Analysis of the interactome of Schistosoma mansoni histone deacetylase 8. PLoS Negl Trop Dis 11 (2017), e0006089.

[389] Y Moné, B Gourbal, D Duval, L Du Pasquier, et al. A large repertoire of parasite epitopes matched by a large repertoire of host immune receptors in an invertebrate host/parasite model. PLoS Negl Trop Dis 4 (2010), e813.

[390] S Castillo-Lara and J F Abril. PlanNET: homology-based predicted interactome for multiple planarian transcriptomes. Bioinformatics 34 (2018), pp. 1016-1023.

[391] S Castillo-Lara, E Pascual-Carreras, and J F Abril. PlanExp: intuitive integration of complex RNA-seq datasets with planarian omics resources. Bioinformatics 36 (2020), pp. 1889-1895. 
[392] J H Konieczka, K Drew, A Pine, K Belasco, et al. BioNetBuilder2.0: bringing systems biology to chicken and other model organisms. BMC Genomics 10 Suppl 2 (2009), S6.

[393] M Zhao, T Wang, K J Adamson, K B Storey, et al. Multi-tissue transcriptomics for construction of a comprehensive gene resource for the terrestrial snail Theba pisana. Sci Rep 6 (2016), p. 20685.

[394] T Hao, Z Zeng, B Wang, Y Zhang, et al. The protein-protein interaction network of eyestalk, Y-organ and hepatopancreas in Chinese mitten crab Eriocheir sinensis. BMC Syst Biol 8 (2014), p. 39.

[395] T Hao, L Zhao, D Wu, B Wang, et al. The protein-protein interaction network of, Litopenaeus vannamei haemocytes. Front Physiol 10 (2019), p. 156.

[396] L Jiao, T Dai, M Jin, P Sun, et al. Transcriptome analysis of the hepatopancreas in the Litopenaeus vannamei responding to the lead stress. Biol Trace Elem Res 199 (2020), pp. 11001109.

[397] A E Velázquez-Lizárraga, J L Juárez-Morales, I S Racotta, H Villarreal-Colmenares, et al. Transcriptomic analysis of Pacific white shrimp (Litopenaeus vannamei, Boone 1931) in response to acute hepatopancreatic necrosis disease caused by Vibrio parahaemolyticus. PloS One 14 (2019), e0220993.

[398] X Wang and Y Jin. Predicted networks of protein-protein interactions in Stegodyphus mimosarum by cross-species comparisons. BMC Genomics 18 (2017), p. 716.

[399] B Müller and U Grossniklaus. Model organisms-A historical perspective. J Proteomics 73 (2010), pp. 2054-2063.

[400] S Richards. It's more than stamp collecting: how genome sequencing can unify biological research. Trends Genet 31 (2015), pp. 411-421.

[401] J J Russell, J A Theriot, P Sood, W F Marshall, et al. Non-model model organisms. BMC Biol 15 (2017), p. 55.

[402] R R da Fonseca, A Albrechtsen, G E Themudo, J Ramos-Madrigal, et al. Next-generation biology: Sequencing and data analysis approaches for non-model organisms. Mar Genomics 30 (2016), pp. 3-13.

[403] S Diezmann, M Michaut, R S Shapiro, G D Bader, et al. Mapping the Hsp90 genetic interaction network in Candida albicans reveals environmental contingency and rewired circuitry. PLoS Genet 8 (2012), e1002562.

[404] S Wuchty, J H Adams, and M T Ferdig. A comprehensive Plasmodium falciparum protein interaction map reveals a distinct architecture of a core interactome. Proteomics 9 (2009), pp. 1841-1849.

[405] K R Brown and I Jurisica. Unequal evolutionary conservation of human protein interactions in interologous networks. Genome Biol 8 (2007), R95.

[406] E L Folador, S S Hassan, N Lemke, D Barh, et al. An improved interolog mapping-based computational prediction of protein-protein interactions with increased network coverage. Integr Biol (Camb) 6 (2014), pp. 1080-1087.

[407] F Tebbji, Y Chen, J Richard Albert, K T W Gunsalus, et al. A functional portrait of Med7 and the mediator complex in Candida albicans. PLoS Genet 10 (2014), e1004770.

[408] J Cui, P Li, G Li, F Xu, et al. AtPID: Arabidopsis thaliana protein interactome database-an integrative platform for plant systems biology. Nucleic Acids Res 36 (2008), pp. D999-1008. 
[409] N M Dheilly, C Adema, D A Raftos, B Gourbal, et al. No more non-model species: the promise of next generation sequencing for comparative immunology. Dev Comp Immunol 45 (2014), pp. 56-66.

[410] Q E Fletcher and C Selman. Aging in the wild: Insights from free-living and non-model organisms. Exp Gerontol 71 (2015), pp. 1-3.

[411] Mark M. Slabodnick, J. Graham Ruby, Sarah B. Reiff, Estienne C. Swart, et al. The macronuclear Genome of Stentor coeruleus reveals tiny introns in a giant cell. Curr Biol 27 (2017), pp. $569-575$.

[412] X Chen, J R Bracht, A D Goldman, E Dolzhenko, et al. The architecture of a scrambled genome reveals massive levels of genomic rearrangement during development. Cell 158 (2014), pp. 1187-1198.

[413] R Ekblom and J Galindo. Applications of next generation sequencing in molecular ecology of non-model organisms. Heredity (Edinb) 107 (2011), pp. 1-15.

[414] D Tagu, J K Colbourne, and N Nègre. Genomic data integration for ecological and evolutionary traits in non-model organisms. BMC Genomics 15 (2014), p. 490.

[415] N Rhind, Z Chen, M Yassour, D A Thompson, et al. Comparative functional genomics of the fission yeasts. Science 332 (2011), pp. 930-936.

[416] A D Foote, Y Liu, G W C Thomas, T Vinař, et al. Convergent evolution of the genomes of marine mammals. Nat Genet 47 (2015), pp. 272-275.

[417] S A Smith, N G Wilson, F E Goetz, C Feehery, et al. Resolving the evolutionary relationships of molluscs with phylogenomic tools. Nature 480 (2011), pp. 364-367.

[418] A Ungaro, N Pech, J-F Martin, R J S McCairns, et al. Challenges and advances for transcriptome assembly in non-model species. PloS One 12 (2017), e0185020.

[419] N J Wickett, S Mirarab, N Nguyen, T Warnow, et al. Phylotranscriptomic analysis of the origin and early diversification of land plants. Proc Natl Acad Sci U S A 111 (2014), E4859E4868.

[420] M Carruthers, A A Yurchenko, J J Augley, C E Adams, et al. De novo transcriptome assembly, annotation and comparison of four ecological and evolutionary model salmonid fish species. BMC Genomics 19 (2018), p. 32. 